Revue

d'ethnoécologie
Revue d'ethnoécologie

$20 \mid 2021$

Un siècle d'ethno-machins : le centenaire de la Revue de Botanique Appliquée

\title{
Un siècle d'étude des relations sociétés-nature
}

Le centenaire de la Revue de Botanique Appliquée

A century studying of nature-society relations. Centennial of the Revue de

Botanique Appliquée

Serge Bahuchet et Catherine Hoare

\section{(2) OpenEdition}

1 Journals

Édition électronique

URL : https://journals.openedition.org/ethnoecologie/8503

DOI : $10.4000 /$ ethnoecologie.8503

ISSN : 2267-2419

Éditeur

Laboratoire Éco-anthropologie

Référence électronique

Serge Bahuchet et Catherine Hoare, "Un siècle d'étude des relations sociétés-nature », Revue d'ethnoécologie [En ligne], 20 | 2021, mis en ligne le 31 décembre 2021, consulté le 06 mars 2022. URL : http://journals.openedition.org/ethnoecologie/8503; DOI : https://doi.org/10.4000/ ethnoecologie.8503

Ce document a été généré automatiquement le 6 mars 2022.

Revue d'ethnoécologie est mis à disposition selon les termes de la licence Creative Commons Attribution - Pas d'Utilisation Commerciale - Pas de Modification 4.0 International. 


\title{
Un siècle d'étude des relations sociétés-nature
}

\author{
Le centenaire de la Revue de Botanique Appliquée \\ A century studying of nature-society relations. Centennial of the Revue de \\ Botanique Appliquée
}

Serge Bahuchet et Catherine Hoare

\section{Introduction}

1 Nous avons souhaité resituer la création de la Revue de Botanique Appliquée (dans la suite du texte abrégée en $R B A$ ) dans le parcours scientifique d'Auguste Chevalier, son fondateur, et dans l'évolution de celui-ci au sein du Muséum national d'Histoire naturelle, sa maison-mère. Le Muséum fut aussi, en France, un foyer de diffusion intellectuelle dans le domaine des relations sociétés-nature, dont la RBA et ses deux successeurs portent témoignage.

2 Ayant été les spectateurs de la dernière partie de cette période, il nous a semblé utile d'en rendre compte, modestement. Plus globalement nous avons senti l'utilité de rappeler les origines des divers courants dont nous sommes les descendants, et qui forment la richesse et la complexité de nos disciplines. Plusieurs d'entre nous les ont vécus, et ainsi ces rappels leur paraitront évidemment superflus car très connus. Mais étant aussi enseignants, nous savons que nos jeunes générations ne disposent pas des mêmes informations. Aussi notre article s'adresse-t-il peut-être avant tout à elles.

3 Nous sommes les héritiers d'un courant délibérément ethnologique, ou anthropologique comme on dit maintenant; aussi notre évocation n'abordera pas la géographie ou l'écologie, sauf incidemment. Notre parcours historico-intellectuel est celui des sciences anthropologiques.

4 Nous replaçons l'expérience du Muséum de Paris dans une trame historique et dans son contexte international, depuis l'inventaire des plantes utiles jusqu'à l'étude des sociétés humaines en relation avec leurs milieux. Apparaît ainsi une diversité d'approches et de 
terminologies dans les différents centres académiques, approches qui cependant s'interpénètrent et s'influencent les unes les autres.

Précisons que nous ne referons pas ici la chronologie des journaux issus de la RBA, plusieurs articles l'ont rapporté et certains dans cette même Revue d'ethnoécologie (cf. Bahuchet 2012, Hoare 2012).

\section{Auguste Chevalier (1873-1956), botaniste-explorateur}

\section{Origines et parcours}

Né en Normandie en 1873 de parents fermiers, Auguste Chevalier a 48 ans lorsqu'il crée en 1921 la Revue de Botanique Appliquée et d'agriculture coloniale, sous-titrée «Bulletin du laboratoire d'agronomie coloniale " (dans la suite du texte abrégée en RBA). Il publie son $234^{\mathrm{e}}$ article dans le premier numéro. Depuis 1911 il est directeur du laboratoire d'agronomie coloniale de l'École Pratique des Hautes Études EPHE «près le Muséum », laboratoire interministériel (Instruction publique et Colonies).

7 Mais cela fait près de 30 ans qu'il passe plus de temps à explorer l'Afrique qu'à résider en France au laboratoire! Depuis 1898, il sillonne l'Afrique occidentale («Soudan français ", du Sénégal au Niger, en Guinée et Côte d'Ivoire, six missions de 1898 à 1911), l'Afrique centrale (la mission Chari-Lac Tchad en 1902-1904', l'Afrique équatoriale en 1911-1912) puis l'Indochine (1913 à 1920). Il a ainsi parcouru près de $40000 \mathrm{~km}$ ! (Figure 1)

Figure 1 : Les missions d'Auguste Chevalier en 1923

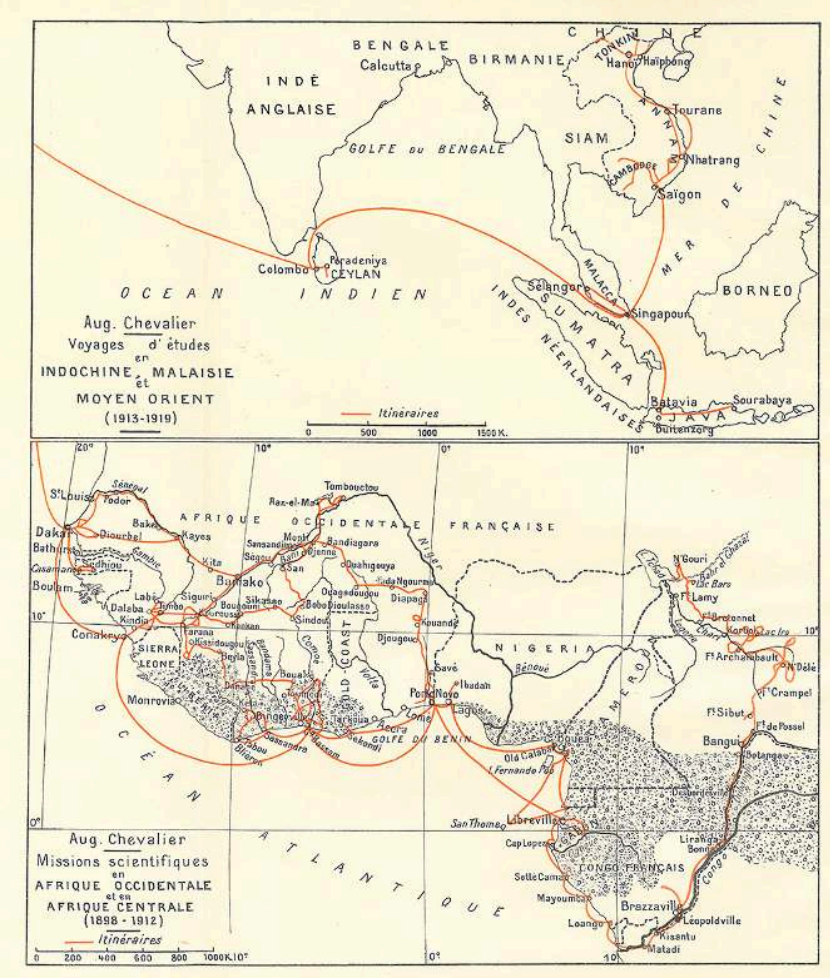

Carte tirée des Titres et travaux (vol. I, 1923, hors texte) 
Entre temps, il a passé sa thèse de docteur ès-sciences naturelles en 1901 au laboratoire de botanique du Muséum, avant d'être chargé de la direction du laboratoire colonial de l'EPHE au Muséum qui avait été fondé en 1897 (Figure 2).

Figure 2 : Auguste Chevalier en 1900, licencié ès sciences, attaché au Muséum, à la veille de sa thèse et de la mission Chari-Lac Tchad

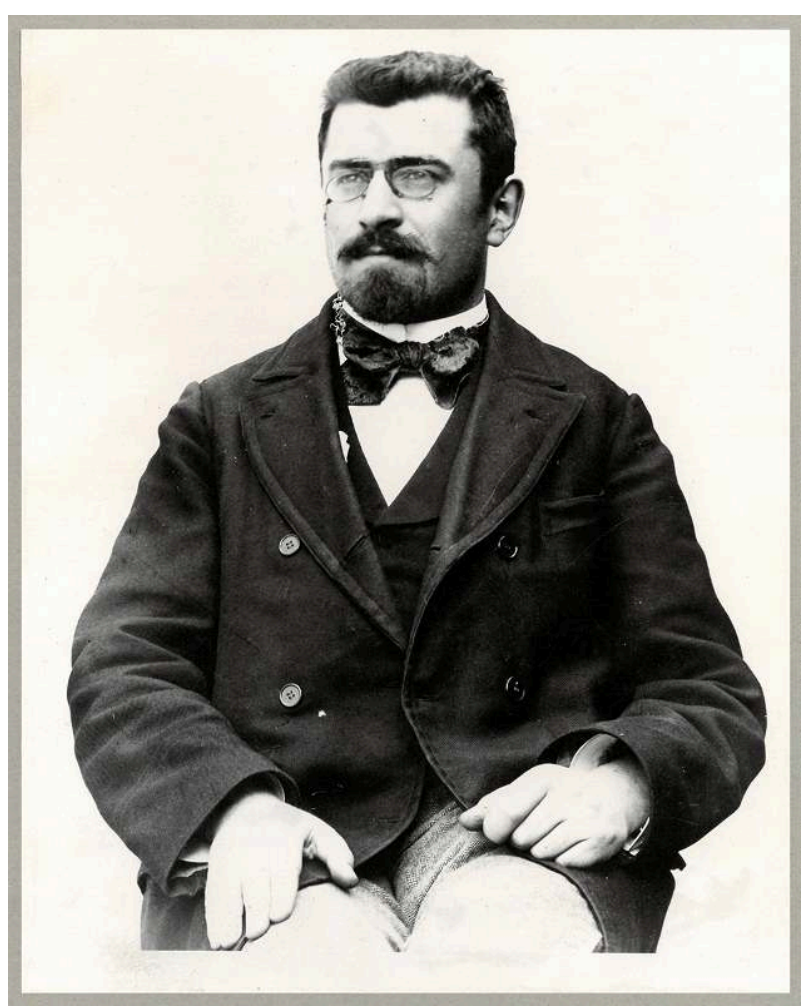

(c) Archives des collections d'ethnobotanique

Pendant toutes ces années, il a souvent été le premier naturaliste à pénétrer des régions inexplorées et à en collecter la flore. Ses récoltes atteignent alors « 39.423 numéros d'herbier " (AC 1923: 35). Il collecte des espèces inconnues, spontanées ou cultivées, il observe et cartographie les formations végétales, mais il s'intéresse aussi aux plantes utilisées par les autochtones, et celles qui peuvent être utiles au développement de ces régions.

En 1911, dans le prolongement de son laboratoire, il est nommé directeur de «la mission permanente d'étude des cultures et des jardins d'essais coloniaux »; c'est à ce titre qu'il est envoyé en Indochine en 1913-1914 puis 1917-1918; après la guerre en 1919, il fait créer l'Institut scientifique de l'Indochine dont il est nommé directeur, avec le jardin botanique de Saigon qui y est annexé (1919-1920). Une cruelle désillusion l'attend à son retour, selon ses propres termes :

«Malheureusement la plupart de ces créations [les jardins botaniques dans les colonies] n'allaient avoir qu'une vie courte et ralentie et leur organisation scientifique allait être délaissée. Dès son retour d'Indochine, en 1919, le Chef de la Mission permanente voyait ses attributions de service créé en 1911 complètement abandonnées et les crédits de son budget réduits à la plus simple expression. Le Chef de Mission ne restait plus qu'un travailleur scientifique isolé, sans lien officiel avec les établissements qu'il avait fait créer ». (AC 1937a : 5) 
11 Par force, Chevalier se stabilise quelque peu et s'efforce de redonner vie à son laboratoire qui avait été délaissé, et très meurtri par les effets de la guerre. La création de la Revue de botanique appliquée et d'agriculture coloniale est l'action qu'il choisit, à la fois pour formaliser et diffuser le projet dont son laboratoire est porteur, et pour maintenir le lien avec la communauté de l'agriculture coloniale, palliant ainsi l'impossibilité de ses missions.

\section{Le contexte de l'agriculture coloniale en France au début du $x^{e}$ siècle}

12 C'est un euphémisme que de dire que l'agriculture coloniale française repose sur une lutte de pouvoir entre le Ministère des colonies et le Muséum, à travers la création du Jardin colonial de Nogent sur Marne en 1898. Celui-ci avait été conçu et porté par le Muséum, à travers la personnalité de son directeur Alphonse Milne-Edward, notamment en donnant un terrain à Nogent et en organisant son programme ; il en a cependant été évincé à la création et ne figure pas dans le décret (cf. L'agriculture pratique... $1901: 3$ ). Il s'ensuivra une longue compétition, et les entreprises, les réussites comme les échecs, de Chevalier doivent être remises dans ce contexte - ses écrits sont d'ailleurs très explicites sur ce sujet (AC 1930, 1935a, 1937a ; cf. aussi Bonneuil 1996).

Comme le rappelle Bonneuil (1999), les chaires naturalistes «à collections » se sont emparées de l'opportunité que représentait la politique coloniale française, pour développer un important programme de missions et d'explorations, dont A. Chevalier est une parfaite illustration. D'ailleurs le Ministère des colonies a financé la création de plusieurs laboratoires soit par l'intermédiaire de l'EPHE, soit directement (Figure 3).

Figure 3 : Les laboratoires et chaires d'origine coloniale au MNHN

\section{Les laboratoires d'origine coloniale}

1897 : Fondation du Laboratoire de biologie coloniale de l'EPHE près le Muséum, renommé en abrégé « laboratoire colonial » en 1901

1911 : Laboratoire d'agronomie coloniale de I'EPHE près le Muséum

1920 : Création de la chaire des «Pêches et productions coloniales d'origine animale » du Muséum

1929 : Création de la chaire des « Productions coloniales d'origine végétale " du Muséum, auquel est rattaché le laboratoire de l'EPHE ; la chaire est rebaptisée Agronomie coloniale en 1933 et Agronomie tropicale en 1958

1942 : Création de la chaire d'Entomologie agricole coloniale, rebaptisée tropicale en 1958

Le Muséum favorise également la création de jardins botaniques dans les colonies, notamment en formant les jardiniers et en distribuant des semences. On verra plus loin le rôle de la chaire de culture dans ces entreprises. Cependant, le Muséum ayant été écarté du Jardin de Nogent, et de l'enseignement qui y a été accolé en 1902 par la 
création de l'École nationale supérieure d'Agriculture coloniale (ENSAC) ${ }^{2}$, c'est cette institution qui prendra ensuite le contrôle des jardins botaniques coloniaux (cf. Bonneuil \& Kleiche 1993, Kleiche-Dray 2000, Volper \& Bichat 2014).

\section{La botanique coloniale appliquée avant la $R B A$}

15 Au tout début du Xx siècle, avaient été créées trois revues techniques avec des objectifs pratiques, destinées essentiellement aux colons souhaitant s'installer et développer des productions agricoles aux colonies.

1) Revue des cultures coloniales (1897-1904)

La première a été fondée par A. Milhe-Poutingon, pour l'Union coloniale française ${ }^{3}$, avec Henri Lecomte comme rédacteur en chef. Dans le comité de patronage, figurent le directeur du Muséum (le zoologue Alphonse Milne-Edwards), le professeur de botanique (Edouard Bureau) et celui de cultures (Maxime Cornu). Le but est d'appuyer la création des jardins d'essai et de «faciliter à nos colons la création et l'exploitation d'entreprises agricoles "; la Revue est conçue pour diffuser des renseignements (MilhePoutingon $1897: 3$ ).

17 Dans la définition du programme, Henri Lecomte précise, en esquissant le tableau « de tous les produits tropicaux que nous demandons à l'étranger et que pourraient fournir nos colonies »:

« ... malgré l'étendue de notre domaine colonial, nous restons les tributaires de tout

le monde; (que) nous demandons presque exclusivement à l'étranger les 180000 tonnes de coton et les 75000 tonnes de jute que l'industrie française manufacture annuellement, et (que) nos colonies produisent à peine la centième partie du café et la vingtième partie du cacao consommés en France ! ( (Lecomte $1897: 4$ ).

2) L'agriculture pratique des pays chauds, bulletin du jardin colonial (1901)

En 1901 est créé L'agriculture pratique des pays chauds, bulletin du jardin colonial et des jardins d'essai des colonies françaises, qui devient en 1913 L'Agronomie coloniale, puis en 1946 L'agronomie tropicale, et depuis1992, Agriculture et développement. Journal officiel de la direction de l'agriculture du ministère des colonies, la première livraison publie l'arrêté du 12 sept. 1900 qui le crée, et en précise le propos (Art. 2) :

«Le bulletin publiera les résultats des études, des recherches et des travaux faits au Jardin colonial ; dans les rapports, comptes rendus de missions agricoles, résultats d'enquêtes; les observations faites dans les jardins d'essai des Colonies, les travaux se rapportant aux questions d'agriculture coloniale émanant de personnes étrangères à l'administration des Colonies, et en général tout ce qui pourra, par sa nature, contribuer au développement et aux progrès de l'Agriculture coloniale. » (L'agriculture pratique... 1901 : 9)

19 Ce bulletin publie des documents officiels, des rapports et des études techniques sur des plantes ou des territoires précis.

20 3) Journal d'agriculture tropicale (agricole, scientifique et commercial) (1901-1919)

Fondé la même année par Jean Vilbouchevitch (1866-1907)4, ce Journal est conçu comme un journal pratique, ainsi qu'un lieu d'échange d'expériences entre colons. II s'adresse explicitement non seulement aux planteurs mais aussi aux "personnes qui ont de l'argent engagé dans des entreprises agricoles en pays chauds (...) » et aux « commerçants qui négocient les produits provenant des colonies et des pays chauds (...)» (1901: 3). Le journal s'occupera de « toutes les grandes cultures tropicales (...), on 
y trouvera des renseignements sur le cocotier, le cacao, le café, ; le thé ; le manioc, les agaves textiles, la canne à sucre (...)».

Parmi ses principaux collaborateurs, sont annoncés Désiré Bois (professeur de culture au MNHN), Auguste Chevalier et Henri Lecomte qui avait quitté la Revue des cultures coloniales. En 1912 Chevalier sera nommé rédacteur du Journal, Vilbouchevitch étant décédé en 1907. Il explique en 1943 l'évolution du Journal et sa relation avec la future $R B A$, à travers le laboratoire.

\section{1, fondation de la Revue de Botanique Appliquée}

C'est donc dans ce contexte institutionnel que Chevalier crée sa revue en 1921, pour prendre la suite de ce dernier périodique, qui n'avait jamais réellement pris de l'ampleur. Toutefois le Journal d'agriculture tropicale a contenu brièvement en supplément le Bulletin du laboratoire d'agronomie coloniale en 1913, puis encore en 1918 pour cesser totalement en 1919 (Hoare 2012).

\section{La botanique appliquée et le programme de Chevalier}

Figure 4 : En-tête du premier numéro de la $R B A$

\section{Revue de Botanique appliquée \\ \& d'Agriculture coloniale \\ Bulletin du Laboraloire d'Agronomie coloniale

\begin{tabular}{lcc}
\hline Vol. I & 13 MAI 1921 & No1 \\
\hline
\end{tabular}

Chevalier explique son projet dans le message « Au lecteur » dans le premier numéro de sa revue, daté du 15 mai 1921, précisant que celle-ci est également le bulletin du laboratoire d'agronomie coloniale (Hoare 2012 : § 18) :

«Ce n'est pas exclusivement d'agriculture tropicale que nous nous occupons dans le laboratoire, mais aussi de l'horticulture coloniale, de la phytopathologie, des forêts et des bois coloniaux, encore imparfaitement connus, toutes questions qui relèvent du domaine de la Botanique appliquée. » (AC 1921 : 1)

Le premier article détaille les sujets sur lesquels le laboratoire travaille : le caoutchouc, le coton, le riz, les théiers, caféiers, camphriers, bois, arbres fruitiers (tant français que tropicaux)...

Auguste Chevalier précise dans sa Notice des Titres et travaux de 1923 :

« Nous avons consacré à la Botanique appliquée, et notamment à l'étude des plantes utiles des colonies françaises une grande partie de notre activité depuis vingt-cinq ans. Nos recherches (...) sur le terrain (...) avaient pour but de déterminer les conditions les plus rationnelles de conservation et d'exploitation des plantes utiles spontanées ou cultivées, d'en faire l'inventaire dans chacune des colonies que nous 
avons traversées, de rechercher les espèces et variétés cultivées, par les indigènes, enfin de déterminer les conditions climatériques et biologiques exigées par certaines grandes cultures tropicales pour réussir, afin de les développer dans les colonies appropriées. » (AC 1923: 89)

Chevalier accorde une attention particulière à la biologie et la systématique des plantes cultivées, aux «bois coloniaux", à "certaines plantes utiles» de France, «à l'acclimatation végétale dans les pays tempérés ». Ainsi, sa Notice comporte des rubriques sur le bois, les plantes à caoutchouc, les cotonniers, les plantes oléagineuses, les caféiers, les arbres fruitiers, les plantes vivrières et des " plantes utiles diverses "!

Lorsqu'en 1929 Chevalier est nommé professeur d'agronomie coloniale au Muséum à la chaire des "Productions coloniales d'origine végétale» qui est alors créée, en transformant la chaire de l'EPHE, il poursuit et même amplifie la publication de la Revue de botanique appliquée et d'agriculture coloniale. Toutefois comme il explique dans sa leçon inaugurale :

«A l'expression 'Agriculture coloniale' généralement admise en France depuis au moins deux siècles, nous préférons l'appellation 'd'Agriculture ou d'Agronomie tropicale et sub-tropicale' et les études dont nous nous occupons intéressent tous les pays à climat chaud, non seulement l'Afrique du Nord, le Sénégal ou l'Indochine, mais aussi l'Afrique du Sud, le Brésil, l'Abyssinie qui ne sont pas des Colonies. » (AC $1930: 15)$.

En conséquence, mais un peu plus tard (1938) il fait évoluer le titre en Revue de botanique appliquée et d'agriculture tropicale, et après sa retraite il en élargit la portée, en Revue internationale de botanique appliquée et d'agriculture tropicale (1947 ; cf. Hoare 2012).

Pendant l'Occupation, Chevalier annonce sa volonté de poursuivre l'effort de publication, en terminant par un texte émouvant :

« Nous avons la volonté de faire tout ce qui sera dans nos moyens pour que l'effort de documentation auquel s'attache la Revue ne soit pas totalement arrêté. Il faut tenir le flambeau allumé quand il a pour but d'orienter les hommes vers un destin meilleur et c'est bien à cela que tend la science des plantes, appliquée à l'agriculture et à l'exploitation rationnelle du sol. Nous irons de l'avant autant qu'il sera possible. Nous publierons dès que nous pourrons la table-index déjà prête pour l'impression. Des manuscrits de travaux prêts à paraître sont rassemblés. Nous voulons que la Revue subsiste.» (AC 1943: 5).

Il a alors 70 ans.

\section{La tradition des naturalistes voyageurs du Muséum}

31 Auguste Chevalier s'inscrit bien évidemment dans la longue et illustre lignée des voyageurs naturalistes qui ont nourri les collections du Muséum, et auparavant celles du Jardin des plantes, en parcourant les terres lointaines et rapportant objets naturalistes et observations sur tous les domaines de l'histoire naturelle, au-delà de leur propre spécialité : Tournefort ${ }^{5}$ en Turquie, Feuillée au Chili, Plumier et FuséeAublet en Amérique, Delile en Égypte, Adanson au Sénégal ${ }^{6}$.. (Cf. Chevalier 1930, 1935a) ${ }^{7}$

La diversité des thèmes qu'il rapporte dans ses Titres et travaux témoigne du fait que la botanique sensu stricto, s'il lui consacre d'énormes collectes, n'est qu'une partie de ses activités. D'ailleurs le fait que ses descriptions de plantes nouvelles n'ont pas souvent été conservées montre qu'il était un taxonomiste quelque peu hâtif ! Et c'est la RBA qui 
témoigne de son labeur acharné pour publier ce qui lui importe finalement le plus, les matériaux sur les plantes utiles, l'agriculture tropicale et la botanique appliquée ${ }^{8}$

Parallèlement, les articles qu'il consacrera aux relations des sociétés indigènes avec les plantes seront publiés ailleurs que dans sa $R B A$, probablement parce qu'il savait que ce n'était pas ce que ses lecteurs attendaient. Il en publiera par exemple cinq dans le Journal des Africanistes (parmi lesquels AC 1934a, 1935b, 1937b), mais aussi 13 dans les Annales de Géographie et sept dans le Bulletin de l'association des Géographes français.

\section{L'étude des plantes au Muséum}

Il semble intéressant de rappeler la place des plantes dans l'histoire naturelle du Muséum. A la fondation du Jardin royal des plantes médicinales en 1635, trois enseignements publics et en français, (" démonstrations»), sont dispensés "tant pour l'instruction des écoliers en médecine que pour l'utilité publique » (extraits du l'Édit royal du 15 mai 1635 , cités par Jussieu $1802: 7$ et suivantes ${ }^{9}$ ) :

"L'intérieur des plantes et de tous les médicaments» (c'est la chimie et la pharmacie)

«L'extérieur des plantes » (c'est la botanique)

«Opérations de chirurgie » (c'est l'anatomie).

L'édit précise que

«la démonstration de l'intérieur des plantes, et des médicaments, tant simples que composés, [...] consiste en l'enseignement de leur essence, propriétés et usages, et [à] travailler manuellement en toutes opérations pharmaceutiques, choix, préparations et compositions de toutes sortes de drogues (...) ».

\section{Finalité du Jardin royal des plantes médicinales}

En 1628, Guy de la Brosse (1586-1641), Conseiller et médecin ordinaire du Roy, rédige un mémoire sur la nature et vertu des plantes qui commence par ces mots, « Au liseur »:

«Poursuivant le dessein de la construction du Jardin Royal des Plantes Medicinales, il m'est venu en pensee de monstrer comme ces estoiles de la terre éstoient puissantes, \& combien elles avoient devancé les autres produits de la Nature de temps, de beauté, de bonté, de diversité \& de vertus... » (1628: n. p.)

Ce gros livre de 680 pages, qui est un véritable traité de botanique appliquée à la pharmacopée, se poursuit par le «Dessein d'un jardin pour la culture des plantes médicinales à Paris ", un projet très détaillé sur plus 200 pages, justifiant le projet auprès du Roy et de ses ministres, en commençant par le premier (Richelieu). Et l'on comprend que ces textes sont des plaidoyers contre « ceux qui voudroient empescher le germe des Plantes de ce Iardin ", ceux qui " ont osé soustenir que quatre vegetaux (...) estoient suffisans pour remedier à toutes les indispositions du corps humain (...) » (p. 757), entendez : l'Université ${ }^{10}$ !

Le Jardin aura deux fonctions, cultiver des plantes médicinales et enseigner leurs vertus :

«Ie propose à Vostre Majesté la construction d'un Iardin pour cultiver les Plantes Medicinales; où vostre Peuple ait recours en ses infirmitez; où les disciples de la Medecine puisent apprendre; \& où ceux qui la professent s'addressent à leur besoin. » (La Brosse $1628: 683$ ).

Il précise qu'il faut fournir des plantes fraîches aux «medecin, chirurgien \& apoticaire ». 
l'enseignement, qui est la démonstration sur les plantes vivantes :

«Personne ne s'y peut rendre expert par la seule lecture des livres, pour assiduë qu'elle soit ; mesme des meilleurs autheurs ; ainsi l'affirme Mathiole, il les faut (ditil) voir \& revoir sur le pied, avec un Maistre entendu \& consommé en leur recherche, les contempler \& gouster és diverses saisons de l'an et de leur aage. » (La Brosse $1628: 760$ ).

Le jardin proposé doit être vaste (plus de cinquante arpents), où

"les Plantes ne seront pas seulement singulières pour l'apprentissage, mais en multitude pour l'usage \& pour fournir à l'experience » (pp. 693-694); « le Iardin est particulièrement construict pour instruire l'aprentif [sic] de Medecine, j'offre de faire leçon des Plantes, donnant connoissance de leurs Synonimes, des lieux où elles croissent, des temps de leur maturité \& cueillette ; les moyen de les conserver, leurs qualitez premieres \& secondes, \& le plus des troisesmes qu'il me sera possible...( La Brosse $1628: 695)$... je promets de faire un cours de l'Art distillatoire ... (La Brosse $1628: 696) » \ldots$

Il précise d'ailleurs que le jardin conservera également des plantes sèches, des résines, des sucs, des eaux distillées, des essences et des sels (La Brosse 1628 : 694-695).

Le dossier se termine par la liste des «plantes usageres» que «l'on doit trouver à toutes occurrences, soit recentes ou seches, selon la saison; au Iardin Royal des Plantes Medicinales; ensemble les sucs, les eaux simples distillees, les sels et les essences. », classées par parties et types (racines, bois, herbes, etc.).

Le projet de Guy de La Brosse est basé sur la certitude que la flore locale renferme des «vertus » mal utilisées, et probablement d'autant de qualité voire plus que les plantes étrangères :

«Ce ne sont pas les herbes estrangeres, rares, \& de grand coust qui recellent seules les principales vertus pour la guerison, il y en a telle foulee en la voye, mille fois plus efficacieuse, que celle que l'avare Marchand par l'esperance de son gain nous apporte de loin \& nous sophistique. Plusieurs paysans le sçavent, \& le bien qu'ils conferent de ces domestiques vegetaux aux pauvres malades, faict qu'ils hochent la teste sur les Medecins, \& se rient des Apotiquaires ». (La Brosse 1628 : 763)

$\mathrm{Au}$ risque d'être totalement anachronique, on pourrait presque déceler là une toute première déclaration pour la reconnaissance et la valorisation des savoirs locaux !

\section{Organisation du Jardin du Roy}

Le Jardin ayant finalement été fondé en 1635 , l'ensemble des démonstrateurs ${ }^{11}$ est placé sous la direction de l'Intendant, lui-même supervisé par un Surintendant, qui est le premier médecin du roi. L'intendant avait la charge du jardin, de ses cultures et du cabinet où est « gardé un échantillon de toutes les drogues, tant simples que composées (...), toutes choses rares en la nature qui se rencontreront, pour servir de règle en toutes autres", devant servir pour les démonstrations, de même que les démonstrations de l'extérieur des plantes sont réalisées dans le jardin.

À partir de 1699, sous la Surintendance de Guy-Crescent Fagon (1638-1718) ${ }^{12}$, la gestion des cultures fera l'objet d'un enseignement confié à un sous-démonstrateur spécifique, Sébastien Vaillant, jusque-là son secrétaire et directeur des cultures. Les intendants successifs, chargés du jardin, Guy de la Brosse puis Fagon, avaient tous deux considérablement élargi le catalogue des cultures en créant un réseau de 
correspondants, chargés de leur procurer des plantes hors de France, en particulier d'Inde et d'Amérique. Ces essais et recherches sur l'acclimatation de plantes exotiques sous le climat parisien se poursuivront en prenant de l'ampleur dans les siècles suivants.

On a là l'origine des directions que prend l'étude des plantes dans cette institution, dès sa fondation.

Le botaniste Tournefort (1656-1708), titulaire de la chaire de botanique au Jardin du Roy en 1683, indique dans ses Elémens de botanique : ou métode pour connoitre les plantes:

«La Botanique, ou la science qui traite des plantes, a deux parties qu'il faut distinguer avec soin; la connoissance des plantes, et celles de leurs vertus». (Tournefort $1694: 1$ )

50 Il précise plus loin, après avoir défini la connaissance des plantes («...précisément savoir les noms qu'on leur a donnés par raport à la structure de quelques-unes de leurs parties. »):

«La connoissance des vertus des plantes qui fait la seconde partie de la Botanique, est sans comparaison plus utile que la première ; mais la connoissance des noms des plantes doit necessairement préceder celle de leurs vertus. Connoître les vertus des plantes, c'est proprement connoître les raports qu'elles ont avec quelques autres corps, \& principalement avec celui de l'homme ». (Tournefort $1694: 2-3$ )

51 Cela relève donc du domaine de la médecine. Et de fait, au Jardin du Roy, c'est la division entre d'une part, "l'intérieur des plantes» et la chimie, et d'autre part "l'extérieur des plantes", qui est la botanique proprement dite que Tournefort est véritablement le premier à s'efforcer de formaliser.

En 1793 à la Révolution, lors de la transformation du Jardin royal des plantes médicinales en Muséum d'histoire naturelle, ce sont quatre chaires entièrement ou partiellement consacrées aux plantes qui seront créées (sur les douze d'origine), héritant des domaines des démonstrations originelles: Botanique dans le muséum, Botanique dans la campagne, Agriculture et culture des jardins, des arbres fruitiers et des bois (par la suite abrégé en "Culture ») $)^{13}$ et Arts chimiques ${ }^{14}$. Le décret de la fondation est explicite en ce qui concerne les fonctions attendues du Muséum :

«Titre premier, article premier: Le but principal de cet établissement fera l'enseignement public de l'histoire naturelle, prise dans toute son étendue \& appliquée particulièrement à l'avancement de l'agriculture, du commerce \& des arts ».

Au fil du temps, l'étude des « vertus des plantes » sort du domaine de la botanique, ce qui suit la ligne ouverte par Tournefort et poursuivie par tous ses successeurs, les Jussieu, Lamarck, etc., pour être prise en charge par la chaire de Culture. Quant à "l'intérieur des plantes ", elle va se transformer d'une part en physiologie végétale, d'autre part en chimie organique (Figure 5). 
Figure 5 : Évolution des chaires de botanique au Muséum (1793-1985)

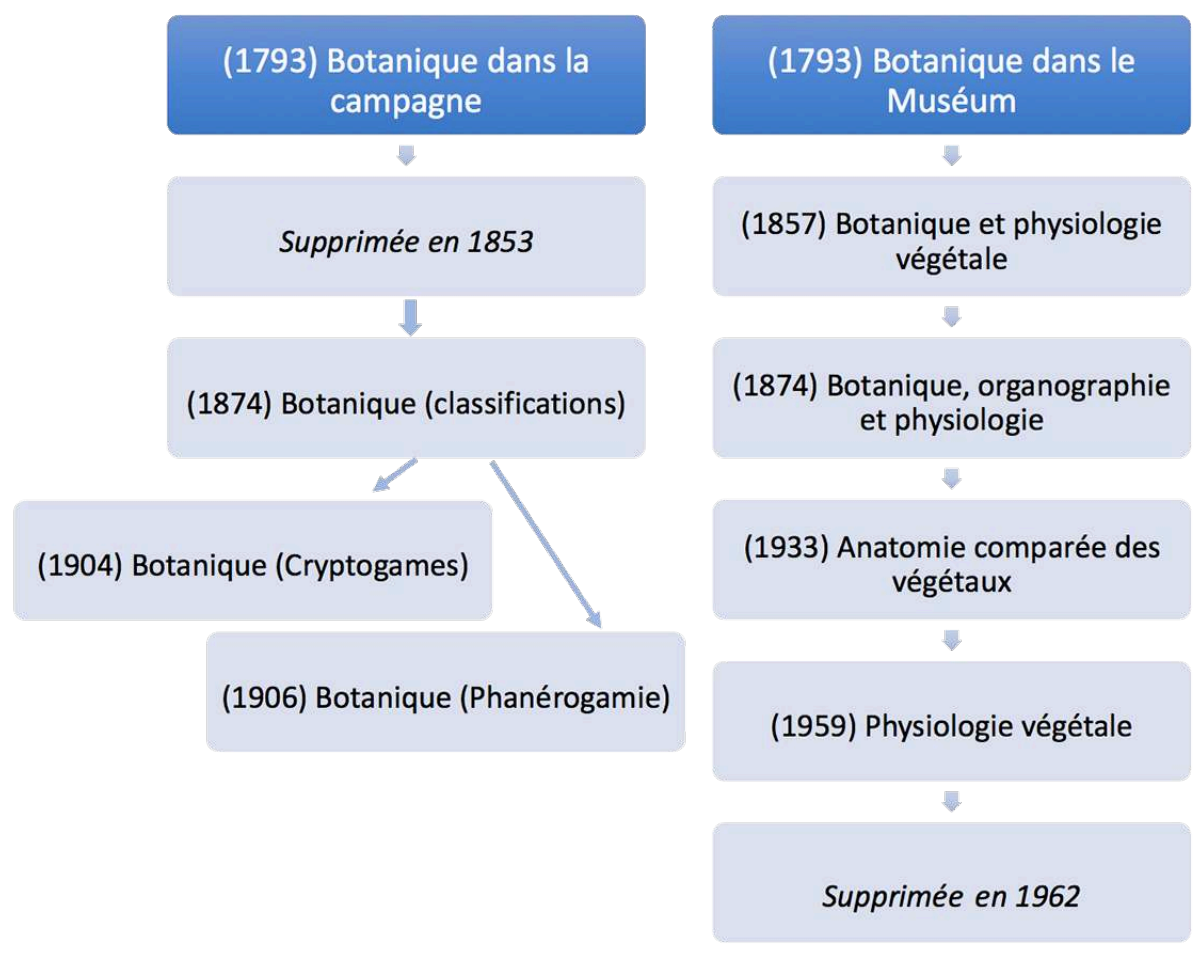

\section{La chaire de Culture}

La chaire d'Agriculture et culture des jardins existe de 1793 à 1956 (cf. Guillaumin 1933 sur l'histoire de cette chaire). Elle est alors renommée Biologie végétale appliquée. En 1985 elle est supprimée et remplacée par un Service des cultures, retrouvant sa simple fonction d'avant 1699 !

Quoi qu'il en soit, quatre personnalités ont marqué son domaine, et en tout premier lieu, André Thouin (1747-1824, professeur à partir de $1793^{15}$ ), qui se concentre sur l'acclimatation des plantes, les échanges entre jardins botaniques sur tous les continents ${ }^{16}$ et sur les techniques de culture (Thouin 1827, Letouzey 1989). Plus proches de la carrière d'Auguste Chevalier, ce sont Maxime Cornu, Désiré Bois et André Guillaumin, le dernier titulaire de la chaire.

Il importe ici de noter le rôle particulier assigné à la chaire de culture, qui fait le lien direct entre la fonction d'enseignement de l'histoire naturelle, et donc les recherches et les collections qui sont nécessaires à sa description, et l'application « à l'avancement de l'agriculture ». Cette chaire en effet étudie les plantes utiles à l'agriculture (mais aussi les plantes ornementales pour les jardins) mais elle a en outre la fonction cruciale de les cultiver dans le Jardin des plantes, en tant que support des démonstrations pédagogiques. Cela est clairement exposé dans le Décret originel de 1793 :

«Titre IV, Art. 3 - le professeur de culture sera chargé de faire parvenir dans les jardins de botanique situés dans les divers départements de la France, les graines des plantes \& des arbres rares, recueillies dans le jardin du Muséum. Ces envois pourront être étendus jusqu'aux nations étrangères pour en obtenir des échanges propres à augmenter les vraies richesses nationales ». (Décret 1793: 6-7 ; cf. aussi Gayon 1997 : 382) 

végétale appliquée qui succède à celle de culture),

« Le laboratoire de Culture groupait une chaire scientifique et un service technique, ce qui associait aux soucis de maintenir à sa place, une des toutes premières, le Jardin botanique du Muséum, ce Jardin des Plantes cher au cœur de tant de Parisiens, les soucis d'en tirer le matériel scientifique exploitable sur place ou utile à tant d'autres chercheurs ». (Hamel 1976 : 89)

Maxime Cornu $^{17}$ (1843-1901, professeur de 1884 à 1901) a joué un rôle fondamental dans l'établissement des jardins d'essais outre-mer et sur la diffusion des semences et des plants dans le vaste réseau de jardins qu'il constitue, tout en formant le personnel technique des jardiniers (cf. Bonneuil 1999). Selon Guillaumin (1933:358), il a distribué « 8644 plantes appartenant à 200 espèces» dans toutes les colonies, ainsi que 427 sachets de grains en moyenne annuelle !

Lorsque Chevalier est nommé professeur, c'est Désiré Bois ${ }^{18}$ (1856-1946, professeur de 1920 à 1932) qui dirige la chaire. Bien qu'il ait longtemps parcouru de nombreuses régions tropicales, jusqu'à Java, rapporté des herbiers et des semences, et enseigné à l'école coloniale de 1896 à 1913 (Capus \& Bois 1912), il se concentre ensuite sur la flore utile tempérée (et non plus sur les jardins tropicaux, comme ses prédécesseurs) et en particulier sur les plantes alimentaires. On sait qu'il a publié Le potager d'un curieux avec Auguste Paillieux (Paillieux \& Bois 1899), résultant de l'acclimatation de légumes exotiques en jardins potagers (et des essais culinaires liés!), et une œuvre conséquente sur les Plantes alimentaires chez tous les peuples et à travers les âges en quatre volumes (Bois 1927-1937).

60 Selon Jean Gayon, la chaire des productions coloniales d'origine végétale est créée en complément de la chaire de culture, pour prendre en charge les échanges avec les jardins tropicaux $(1997$ : 384, 397). Cela peut expliquer pourquoi Bois s'est concentré sur la flore tempérée, d'autant qu'à cette époque, comme on l'a dit, le rôle du Muséum envers les jardins coloniaux s'est considérablement réduit.

61 Le dernier titulaire de la chaire de culture a donc été André Guillaumin ${ }^{19}$ (1885-1974). Au départ «botaniste-systématicien », selon ses termes, spécialiste reconnu de la flore de Nouvelle Calédonie où il voyage longuement d'abord dans les herbiers puis sur le terrain ${ }^{20}$, il se fera «jardinier-systématicien » en prenant la charge de la chaire de culture. Outre ses actes dans la replantation du Jardin, la recomposition des grandes serres, la création du jardin alpin et du parc écologique, Guillaumin appliquera sa science de taxonomiste à la mise en place d'une nomenclature horticole. Il s'intéresse beaucoup à la flore horticole, à laquelle il consacre plusieurs ouvrages, sur les cactées cultivées, sur les plantes tropicales et tempérées ${ }^{21}$ Ce botaniste complet, «fort érudit " selon l'expression de Hamel, s'intéresse évidemment aux plantes utilisées dans le Pacifique, son terrain d'élection. Il était très lié au laboratoire de Chevalier et peut-être plus encore à celui de Portères, et il a d'ailleurs publié dans la RBA (entre autres Guillaumin 1923, 1944) et une vingtaine d'articles dans le JATBA, dont l'un avec A.-G. Haudricourt (Guillaumin 1970, Guillaumin \& Haudricourt 1961, Guillaumin \& MacKee 1956). 


\section{La Botanique des phanérogames au Muséum}

En préliminaire, nous aimerions mentionner ici cet extrait des Conseils aux voyageurs naturalistes du Muséum :

«De tous temps, les professeurs chargés des collections botaniques ont demandé aux voyageurs de rapporter des produits végétaux. 'Nous comprenons sous cette désignation, disait A. Brongniart (...), toutes les parties des végétaux ou produits du règne végétal qui offrent de l'intérêt ou méritent d'être recueillies: tels sont les fibres employées pour la fabrication des tissus ou des cordages, les tissus naturels provenant de la préparation du liber des arbres, les papiers faits directement avec certaines plantes, les fécules, en y ajoutant les tubercules, racines, tiges ou graines dont on les extrait, les gommes, sucres, résines, cires végétales et autres sucs concrétés que fournissent les végétaux, les matières tinctoriales, enfin les racines, écorces, feuilles ou fruits employés soit en médecine, soit dans les arts industriels. », tous « objets » auxquels il faut adjoindre un échantillon en herbier et « indiquer avec soin le nom vulgaire tant de la plante que de la matière employée, et les usages auxquels on l'applique ». (Filhol 1894 : 207-208)

On voit ainsi que dans la grande tradition du Muséum, les usages des plantes devaient être documentés. Chevalier l'avait prise à son compte pour le programme de son laboratoire concernant les tropiques, ainsi que ses collections en témoignent.

Auguste Chevalier avait commencé ses travaux au Muséum pour sa thèse, en 1897, dans le laboratoire de botanique, organographie et physiologie végétale, sous la direction du professeur Philippe Van Tieghem, botaniste très respecté qui a formé de nombreux disciples. Chevalier conservera toujours des liens avec les deux chaires de botanique, et tout particulièrement celle de classification et familles naturelles de phanérogames (qu'il appelle d'ailleurs « chaire des herbiers "!), et à laquelle il confie ses innombrables collectes (cf. Bahuchet et al. 2019). Il noue des relations d'amitié respectueuse avec les deux titulaires dont il fut contemporain, Henri Lecomte (1856-1938)22 puis Henri Humbert (1887-1967) ${ }^{23}$, lesquels seront en retour très bienveillants envers la chaire d'agronomie tropicale. Il faut aussi souligner que tous les deux se sont intéressés aux plantes des régions tropicales, dont les plantes utiles, avant d'être nommés professeurs de botanique.

Ainsi, quand Chevalier arrive et obtient la création de sa chaire, il reprend donc de facto la tradition des plantes utiles. En effet, celles-ci n'étaient plus réellement prises en compte dans le Muséum, voire quelque peu marginalisées (évolution des cultures vers la physiologie, et recentrement vers la pratique dans le jardin des plantes ...), à mesure que les botanistes, quels que soient leurs travaux antérieurs se concentrent sur... la botanique!

\section{La place des «plantes utiles » dans la botanique}

Élargissons le propos, sans craindre un retour en arrière dans la chronologie. Ce qui s'est déroulé au Muséum suit complètement l'évolution de la science botanique. On sait que celle-ci émerge difficilement et lentement de la description des qualités des plantes à finalité médicinale, conduite par les grands ancêtres fondateurs, Théophraste (v. 371-287 av. JC, Histoire des plantes), et ensuite Dioscoride (40-90 ap. JC, De materia medica). Pendant plusieurs siècles, les savants s'efforceront de reconnaître quelles plantes étaient inscrites dans les écrits antiques, en compilant les écrits successifs, sans 
réellement observer ni décrire les plantes, ni s'écarter de l'utilité médicale. On peut dire un peu schématiquement que jusqu'au $\mathrm{XvI}^{\mathrm{e}}$ siècle, botanique et " ethnobotanique " sont confondues (sur l'histoire de la botanique voir Arber 1912, Magnin-Gonze 2009, Drouin 2008 : ch. 2).

\section{Les matières médicales : entre médecine, botanique et chimie}

On a vu comment l'étude des plantes médicinales était aux origines mêmes du Jardin du Roy et donc du Muséum. Tout au long du xvi siècle, et encore au-delà, les voyages d'exploration mettent en contact les savants médecins qui les réalisent avec des flores nouvelles dont ils cherchent à décrire les bienfaits. Nous en citerons deux exemples concernant les terres de part et d'autre de l'Europe : l'Inde (dite alors «orientale ») et l'Amérique (ou «Indes occidentales»). Ces deux ouvrages accordent une attention plus que succincte à la description des plantes et ne donnent la liste que des plantes utiles, dans la tradition héritée de l'Antiquité.

Garcia de Orta (1501-1568) était le médecin du Roy du Portugal ; il séjourne à Goa de 1534 à sa mort en 1568 et y publie son ouvrage : Coloquios dos simples, e droga he cousas mediçinais da India... (Goa 1563), dont le titre complet donne le programme du livre qui résulte de ses observations directes : « ... e assi dalgunas frutas achadas nella onde se tratam algunas cousas tocantes amediçina, pratica, e outras cousas boas ". Il est rédigé sous forme de dialogues entre Orta et un docteur nommé Ruano. Au début du premier dialogue, Ruano explique de la manière suivante ce qu'il attend d'Orta, "parce vous ou des personnes dignes de foi les avez vues $»$ :

«[...] j'ai grand désir de connaître les drogues médicinales (celles que l'on appelle là-bas au Portugal d'apothicairerie), les autres remèdes simples que l'on y trouve, ainsi que tous les fruits, le poivre et toutes ces choses dont je voudrais apprendre les noms dans toutes les langues, les terres où elles croissent, les arbres ou les plantes qui les produisent, et la matière dont en usent les physiciens indiens. Je voudrais encore connaître d'autres plantes et fruits de ces contrées, même s'ils ne sont pas médicinaux, et encore les coutumes de cette terre ou les événements qui s'y sont produits, car toutes ces choses doivent être dites en vérité, telles que vous ou des personnes dignes de foi les avez vues $»^{24}$ (Dr Ruano qui s'adresse à Orta, 1563 ; trad. Messinger Ramos et al. 2004 : 27-28).

Le second ouvrage est dû à Nicolás Monardes ( 1493-1588), médecin à Séville, qui recueille soigneusement les «choses" qui abordent au port, transportées par les navires en provenance du Nouveau Monde. Son livre est paru en 1580, il est consacré aux «choses que l'on rapporte de nos Indes occidentales et qui servent pour la médecine (" las cosas que se traen de nuestras Indias Occidentales, que sirven en Medicina ", Monardes 1580). Le paragraphe "Medicinas que embian nuestras Indias", au début du livre, exprime assez clairement les bienfaits que l'on attend des plantes inconnues rencontrées dans ces terres nouvelles :

"Au-delà de si grandes richesses, nos Indes occidentales nous envoient nombre d'arbres, de plantes, d'herbes, de racines, de gommes, de fruits, de graines, de liqueurs et de pierres qui ont de grandes vertus médicinales et dans lesquelles on a trouvé et on trouve de très grands effets qui excèdent en valeur et en prix tout ce que l'on vient de dire, elles sont d'autant plus excellentes et nécessaires qu'elles donnent la santé au corps plus que des biens temporels: de ces choses, tout le monde manquait, et ce n'est pas un peu par notre faute, on tire de grands profits à les utiliser, non seulement dans notre Espagne, mais dans le monde entier ». (Monardes 1580, p. 1, Vं ; trad. F. Aubaile-Sallenave) ${ }^{25}$ 
70 À la même époque, le Roi d'Espagne Philippe II confit une mission à son médecin, Francisco Hernández (1515-1587), pour réunir les informations sur la médecine de la Nouvelle Espagne. Il séjourne et travaille au Mexique de 1572 à 1577, malheureusement son œuvre immense ne sera finalement compilée et publiée qu'en 1651 sous le titre Thesaurus des choses médicales de la Nouvelle Espagne (Rerum medicarum Novae Hispaniae thesaurus). Cette somme, conçue selon le modèle de l'Histoire naturelle de Pline (que Hernandez avait traduite auparavant), aborde les plantes mais aussi les animaux et les minéraux. À la différence des deux précédents ouvrages (celui de Orta et celui de Monardes), le livre de Hernández se distingue en se basant sur la nomenclature aztèque, et en étant accompagné de planches assez précises pour chaque plante, palliant ainsi le caractère assez succinct des descriptions.

71 La transition de la matière médicale vers la botanique proprement dite est effectuée par le savant médecin italien Pietro Andrea Matthioli (ou Matthiolus, aussi Matthiole, Mattiole, 1501-1578), qui publie des commentaires fortement annotés de Dioscoride Commentarii in libros sex Pedacii Dioscoridis. Cet ouvrage de botanique médicale et surtout sa traduction en italien sont accompagnés d'innombrables planches, très à jour des découvertes de son temps, et qui seront durablement reproduites. L'ouvrage a été réimprimé de nombreuses fois, de ce fait il a eu une influence considérable sur l'évolution de la botanique.

72 Nous nous attarderons sur l'œuvre de Jacques Dalechamp ou Daléchamps (1513-1588), Historia generalis plantarum (1586-1587) qui pourrait être considéré comme l'un des derniers savants de la tradition des Herbaria. Son ouvrage, où chaque plante est illustrée, est basé sur les commentaires de Théophraste et de Dioscoride, mais prenant en compte les ouvrages botaniques de son temps, Matthiolus, Lobelius, Dodoens, Ruellius, Clusius, Fuchs..., avec certains desquels il était en correspondance. Il a aussi inclus le résultat de ses propres herborisations dans la région de Lyon, notamment. Son livre accorde une place très importante aux plantes cultivées. La présentation en est très originale, qui commence par les milieux où l'on rencontre les plantes, en premier lieu les forêts et les arbres « qui croissent sans être plantés ", puis les haies, buissons et les arbustes, puis les vergers, ensuite les champs y compris les herbes croissant "pesle mesle avec les bleds emmy les champs labourez ${ }^{26}$, ensuite les "herbes potagères " des jardins, les herbes recommandées pour leurs belles fleurs, les plantes odorantes à bouquets... Les livres suivants présentent les plantes par milieux de vie (marécages, bord de mer, dans les pierriers, et enfin par morphologie (avec des ombelles, les lianes («plantes qui ne peuvent tenir droites sans être appuyées»), avec des épines, bulbeuses. Les trois derniers livres concernent les plantes purgatives, vénéneuses et les plantes étrangères. On voit que l'organisation est pour partie "écologique ", pour partie morphologique et pour partie enfin utilitaire, mais sans être médicinale ${ }^{27}$.

73 Son Histoire générale des plantes était bien connue. De notre point de vue, les détails qu'il donne sur les plantes cultivées, avec des illustrations, les descriptions et les listes de variétés le rapprochent fortement de la botanique agricole. En ce sens, on peut considérer que Daléchamps fait une transition entre la botanique médicale philologique des Herbaria, et les traités de botanique descriptive qui apparaissent. 


\section{La naissance de la botanique} temps, comme en témoignent les traductions latines qu'il fit de livres portugais ou espagnols, comme le Coloquios dos simples (...) da India (1563) du médecin Garcia de Orta (ou del Huerta) déjà cité, qu'il a traduit en 1567 (Aromatum et simplicium aliquot medicamentorum apud Indos nascentium historia). Son ouvrage ultime est assez émouvant en ce qu'il traite de plantes nouvelles qui lui sont parvenues sous formes de graines ou de fragments, ainsi que des animaux, quelques-uns vivants, d'autres desséchés, provenant d'outre-mer, et qu'il s'efforce de décrire et de reconnaître. C'est Exoticorum libri decem : quibus animalium, plantarum, aromatum, aliorumque peregrinorum fructum historiae describuntur (1605). Cet ouvrage contient des descriptions par Clusius lui-même, mais aussi les traductions latines de Orta, Monardes et Belon. Clusius produit d'ailleurs une belle gravure de Papas peruanorum dans son Rariorum plantarum historia de 1601 (page lxxix), qui serait la première image de cette plante ${ }^{28}$.

78 C'est donc à cette période que la botanique se sépare de la matière médicale. Un siècle plus tard, Tournefort marque une étape cruciale avec ses Elémens de botanique déjà cités (1694) ; le point de non-retour est conclu avec la parution de Genera plantarum par Linné (Carl von Linné, 1707-1778) en 1735 puis son Systema naturae en 1753.

79 Cependant, ces deux illustres botanistes montrent leur intérêt pour les qualités médicinales des plantes, mais dans des ouvrages spécifiques : Tournefort dans sa flore des environs de Paris où il détaille les vertus et les propriétés des plantes (1698), comme Linné applique sa taxinomie et sa classification dans sa Materia medica (1787).

$\mathrm{Au} \mathrm{XVIII}^{\mathrm{e}}$ siècle donc, la botanique se dissocie définitivement de la quête des plantes utiles, ce qui deviendra la botanique appliquée, et de la pharmacopée, qui sera la phytochimie. 


\section{L'émergence de la botanique économique au XIX siècle}

81 En 1813, Augustin Pyrame de Candolle (1778-1841) définit la Botanique appliquée, dans sa Théorie élémentaire de la botanique. Il divise en trois parties « la Botanique, ou histoire naturelle du règne végétal »: la botanique descriptive, la physique végétale ou botanique organique et enfin la botanique appliquée. Cette dernière consiste en :

«l'étude des rapports qui existent entre les végétaux et l'espèce humaine, ou la Botanique appliquée ; elle comprend, $1^{\circ}$ la Botanique agricole; $2^{\circ}$ la Botanique médicale ; $3^{\circ}$ la Botanique économique et industrielle ; $4^{\circ}$ la Botanique historique, etc. ». (1813:20)

À côté de ses nombreux travaux de botanique descriptive, lui-même a abordé la botanique médicale dans un ouvrage particulier, en posant une théorie de l'existence d'une analogie entre les propriétés et les formes extérieures des plantes (1816).

A. Chevalier s'inscrit dans cette filiation en utilisant le terme de Botanique appliquée, et sa revue prend en compte la botanique agricole et la botanique économique. En revanche, dans le monde scientifique anglophone c'est le terme Economic botany qui prédomine.

\section{Les plantes cultivées}

On s'autorisera ici une parenthèse en dehors du fil chronologique. Le propre fils d'Augustin Pyrame de Candolle, lui-même un très grand botaniste, Alphonse de Candolle ${ }^{29}$ (1806-1893) a produit un ouvrage majeur, L'origine des plantes cultivées (1883), qui marque une étape notoire dans l'étude des relations des hommes avec les plantes. Il avait abordé ce sujet dès 1855 dans son grand Traité de géographie botanique raisonnée $e^{30}$ Reprenant ce sujet trente ans plus tard, il le renouvelle en actualisant les données scientifiques, ce qui justifie ce nouveau livre à part entière. Il en expose les principes dans sa préface : «Mon but a été surtout de chercher l'état et l'habitation de chaque espèce avant sa mise en culture. ", ce pour quoi il mobilise de nombreuses sciences, outre la botanique, l'histoire, l'archéologie, la linguistique, la philologie... différentes «méthodes " qu'il est nécessaire de "combiner» (1883: 20). Ce faisant, il fonde une démarche qui deviendra un courant de recherche à part entière, toujours valable pour la recherche toujours inachevée de la quête des origines - à cet ensemble c'est simplement ajouté une nouvelle science, qui n'existait pas encore en son temps, la génétique. Et aujourd'hui encore, nous savons qu'une seule discipline isolée ne peut résoudre ce mystère des origines.

Chevalier s'est toujours posé des questions sur l'origine des plantes cultivées, comme il le dit lui-même dès 1901 : «La recherche de l'origine des plantes cultivées est une des parties les plus obscures de l'histoire de la dispersion des végétaux à la surface du globe ». (1901 : 284). Il a accueilli de nombreux articles sur cette question dans sa revue. Lui-même a réfléchi sur le Sahara comme zone d'origine de plantes cultivées (AC 1901, 1932), un thème encore en suspens. Chevalier publie des conférences de Vavilov et il demande à André G. Haudricourt, à son retour de séjour à Léningrad et qui lisait le russe, de résumer, de faire des compte-rendu et de traduire les travaux de Nicolaï Vavilov (dans RBA 1936 XVI $\left.(174,175,176)^{31}\right)$. Quant à nous, nous avons souvenir que le portrait de Vavilov était accroché dans le bureau de Jacques Barrau. 
86 Nous ajouterons ici un avis personnel : si les centre d'origines sont de mieux en mieux précisés, après N. Vavilov puis J. Harlan, ce sont les routes et les circuits d'introduction des plantes sur les divers continents qui restent extrêmement méconnus. Savons-nous quand et comment le tabac (américain) arrive en Afrique, ou le bananier (océanien) en Amazonie?

87 Fermons la parenthèse et reprenons le fil chronologique.

\section{Aux Jardins botaniques royaux de Kew}

Lorsqu'il prend la direction du jardin botanique de Londres en 1841, William J. Hooker (1785-1865) y crée un Museum of economic botany qui ouvre au public le 20 septembre 1847. En 1849, en prévision des collections devant nourrir son musée, il écrit dans le Manual of scientific enquiry, destiné aux navires de Sa Majesté et aux voyageurs en général :

«Another important branch of the science comes to be mentioned, hitherto much neglected, but towards which travellers will do well to contribute-we mean the museum of vegetable products, or it may be called the "Museum of Economic Botany." Its design is to bring together in one spot and to exhibit those interesting vegetable products from all parts of the world which cannot be shown in the living plants of a garden or the preserved ones of an herbarium ». (Hooker $1849: 405$ )

Il détaille ensuite les éléments qui intéressent les collections, gommes et résines, produits pour la teinture, substances médicinales, et " general products of vegetables", impossible à énumérer dit-il, et qui comprennent aussi bien du papier que des sucres ou des laques... et pour lesquels il recommande de collecter divers stades de la préparation.

Le premier guide des Jardins de 1851 explique que ce Museum, « encore en formation », dispose néanmoins d'une collection de substances végétales intéressantes et économiques qui s'accroît rapidement ${ }^{32}$ :

"This Museum is yet in its infancy, and is destinated to receive all kinds of Fruits and Seeds, Gums, Resins, Dye-stuffs, Drugs, Sections of Woods, and all curious vegetable products, especially those that are useful in the Arts, in Medicine, and in Domestic Economy; such interesting vegetable substances, in short, as the living plants cannot exhibit." (Hooker 1851: 48)

91 Et l'on retrouve donc là les recommandations aux voyageurs de 1849, qui posaient de fait le programme de la botanique économique. Le guide du Museum de 1855 est tout à fait explicite. En complément du jardin, ce Museum a été conçu pour que le visiteur puisse voir d'une part les plantes entières et vivantes dans le jardin et dans les serres, et d'autre part contempler dans un autre bâtiment les produits de ces plantes, pour voir " the uses which the ingenuity of man has derived from them ", comme :

«... a deposit for all kinds of useful and curious Vegetable Products, which neither the living plants of the Garden nor the specimens in the Herbarium could exhibit ; and that such a collection would render great service, not only to the scientific botanist, but to the merchant, the manufacturer, the physician, the chemist, the druggist, the dyer, the carpenter and cabinet -maker, and artisans of every description, who might here find the raw material (and, to a certain extent, also the manufactured or prepared article) employed in their several professions, correctly named, and accompanied by some account of its origin, history, native country , etc., either attached to the specimens or recorded in a popular catalogue ». (1855: 3 , preface) 
L'entreprise de Hooker coincide avec deux ouvrages populaires en Grande Bretagne : celui de John Lindley Medical and Economical Botany (1849), suivi par celui de Thomas Croxen Archer Popular Economic Botany or description of the botanical and commercial characters (1853) (cf. Cornish 2013). Le livre de Lindley est la suite d'un volume général sur la botanique, qu'il a conçu sur le plan de la Materia medica de Linné, organisé selon la classification botanique, avec une illustration pour chaque plante. Inversement le livre d'Archer, consacré aux «produits commerciaux issus du monde végétal » (" commercial products of the Vegetable Kingdom ») présente les plantes selon les usages, avec 20 planches récapitulatives.

muséale et thématique de William Hooker a été poursuivie par son fils Joseph (1817-1911) qui lui a succédé à la direction des Jardins royaux en 1865 (après en avoir été directeur-assistant à partir de 1855). Non seulement il a rapporté des collections de botanique économique de tous ses propres voyages, mais il a suscité le don de nombreuses et importantes collections, des milliers de spécimens, tout au long de sa mandature (cf. Goyder et al. 2012) ${ }^{33}$

Les Hooker père et fils entretiennent des relations intenses avec de nombreuses institutions et en particulier par des dons et des échanges de collections. Ces relations ont comme conséquence de diffuser la notion de «collections de botanique économique ", qui s'accompagne par la création de Museum of economic botany sur le modèle de Kew (cf. Cornish 2013, Cornish \& Nesbitt 2014). En particulier, dès 1858, le botaniste américain Asa Gray, professeur d'histoire naturelle à l'Université de Harvard, demande à W. Hooker de lui envoyer du matériel en double, en vue d'établir un "Museum of vegetable products", qui finalement ne sera établi qu'en 1878 (Schultes 1984 : 1). Ce sont des dizaines de milliers de spécimens que Hooker et ses successeurs envoient aux autres muséums à la fin du XIX ${ }^{\mathrm{e}}$ siècle (Nesbitt \& Cornish 2016 : 61) ! C'est aussi sur l'exemple du Museum de Kew que le New York Botanical Garden va ouvrir son propre Museum of economic botany en 1899, à partir des collections de matières médicales réunies par $\mathrm{H}$. Rusby.

Après ce succès mondial des musées de botanique économique, liés soit aux jardins botaniques soit aux universités, en Grande Bretagne, aux USA, même en Australie et en Inde, ils vont être lentement délaissés après la $2^{\mathrm{e}}$ guerre mondiale, relégués dans des espaces plus petits voire dans les greniers, même aux Jardins de Kew, jusqu'à être totalement effacés; dans certains cas les collections sont distribuées entre différents musées (dont ceux d'ethnologie) ou même détruites... Nesbitt \& Cornish (2016) expliquent ainsi le déclin de ces musées à la fin des années 1950 :

«We suspect that the factors apparent at Kew operated elsewhere; in the post-war period, economic botany collections doubtless appeared old-fashioned, particularly as specimens were often housed in glass jars or glass-topped boxes of antique appearance; industrial and public interest in natural products was on the wane, in an era when oil-based products appeared more modern ». (Nesbitt \& Cornish 2016 : 63)

Le Muséum d'histoire naturelle de Paris reste totalement en dehors de ce mouvement. Il n'y avait nulle part où la botanique en tant que telle fut exposée, alors qu'il y avait des galeries d'anatomie, de géologie, de paléontologie et de zoologie, tout autour du jardin botanique. Les laboratoires successifs de culture et de botanique n'avaient pas d'autre expression publique que le jardin des Plantes lui-même et les cours et démonstrations en amphithéâtre. En ce qui concerne les sciences de l'Homme, 
l'anthropologie biologique était incluse dans la galerie d'anatomie, alors que l'ethnographie et les artefacts humains n'étaient ni collectés en tant que tel ni surtout exposés, raison par laquelle le professeur d'anthropologie Ernest Hamy a créé, en dehors du Muséum, un musée indépendant, le Musée d'ethnographie du Trocadéro (MET) en 1878 (Hamy 1988). Mais dans le programme du MET ne figurent pas les objets et spécimens relevant de la botanique économique, tels que ceux qui étaient et sont encore conservé à $\mathrm{Kew}^{34}$

97 Au Jardin des Plantes à Paris, Auguste Chevalier ouvrira dans son laboratoire (Figure 6), à une date inconnue, une "galerie d'agronomie coloniale " sur un modèle similaire (mais apparemment sans objets ethnographiques) mais celle-ci n'a pas survécu - au point que nous n'en avons pour l'heure mis en évidence aucune documentation, autre que la photo! (Figure 7)

Figure 6 : La façade de l'ancien laboratoire d'agronomie coloniale, envahie par la vigne-vierge, en 1932

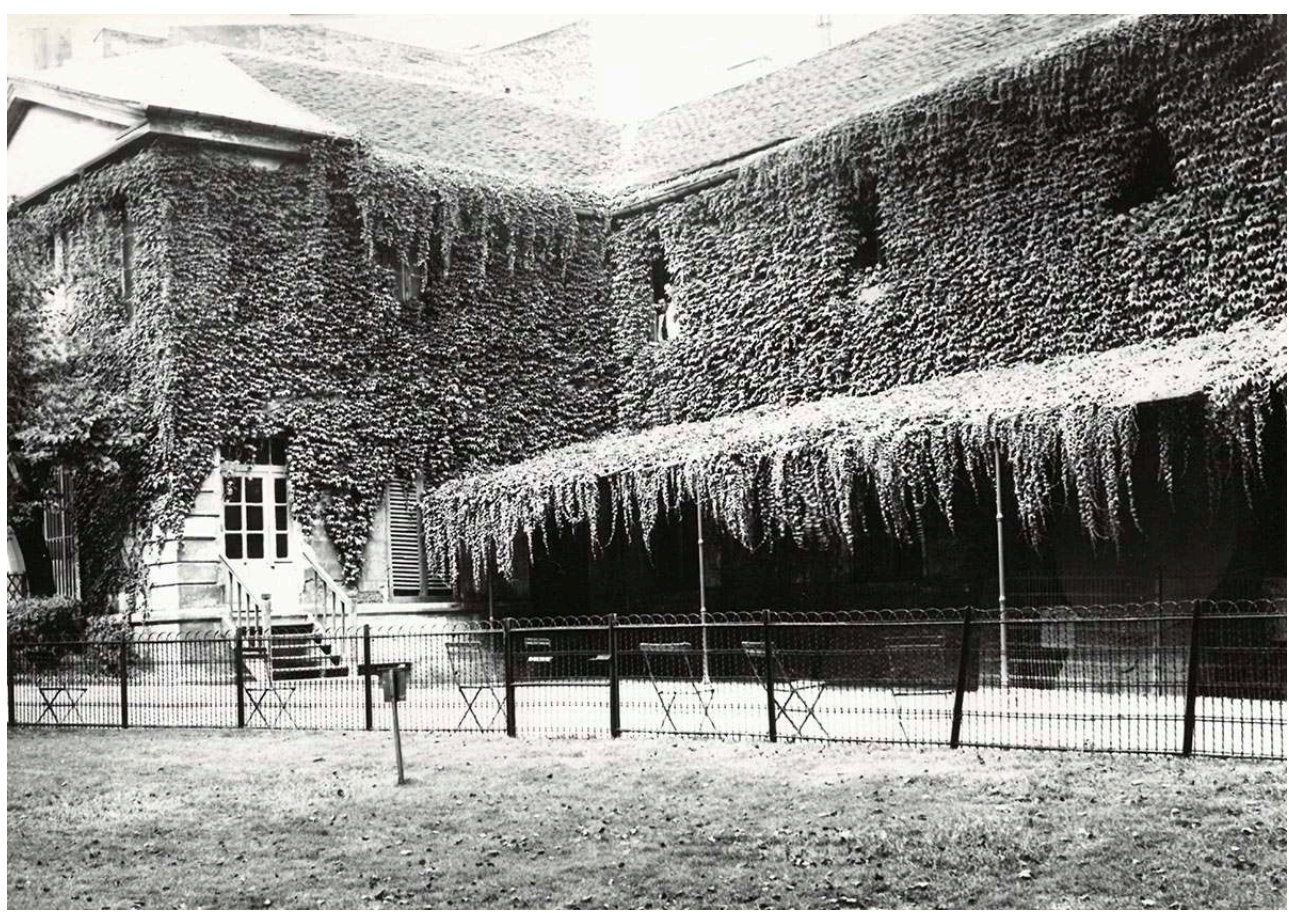

(c) Archives des collections d'ethnobotanique 
Figure 7 : La galerie du laboratoire d'agronomie coloniale

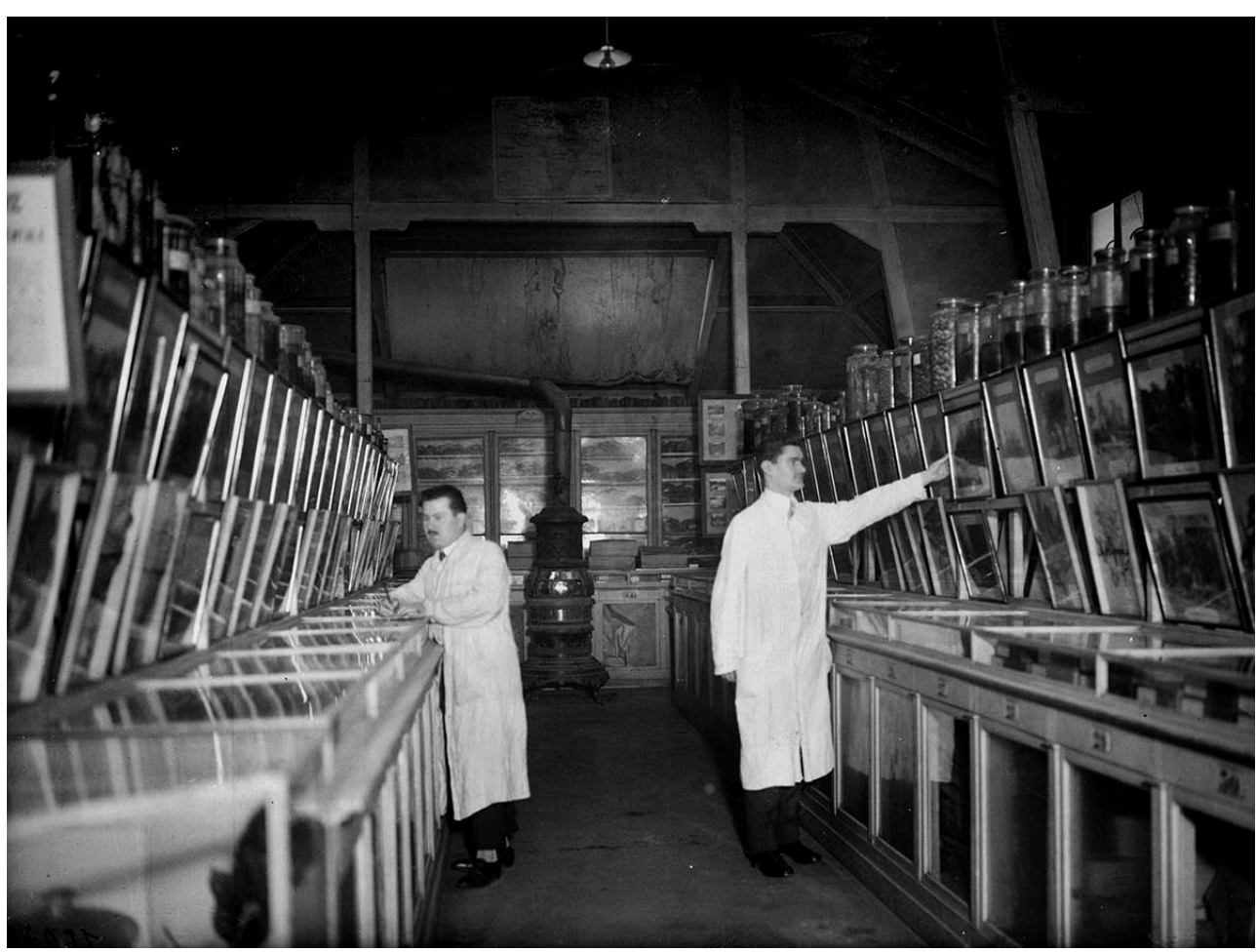

(c) Jacques Boyer/ Roger-Viollet

\section{Les ressources végétales commerciales}

Accompagnant la mise en place des empires coloniaux, un important courant se développe dans la seconde moitié du XIX siècle, plus intense qu'antérieurement, pour l'inventaire des ressources végétales d'importance commerciale. On peut en citer deux exemples caractéristiques concernant l'Inde: The useful plants of India; with notices of their chief value in commerce, medicine, and the arts, du Colonel Heber Drury (1873) et vingt-cinq ans plus tard, l'immense Dictionnary of the economic products of India, en 6 volumes, de George Watt (1889-1896) ${ }^{35}$. Dans ces deux ouvrages, les plantes sont présentées alphabétiquement.

99 Une autre personnalité marquante est liée à G. Watt, c'est le botaniste Isaac H. Burkill (1870-1965), qui fut le secrétaire de Watt à l'Indian Museum de Calcutta. Il fut ensuite le second directeur du Jardin botanique de Singapour de 1912 à 1925, où il développa la recherche et planta la section économique du jardin. Il commença ses travaux par des études assez classiques sur une multitude de plantes utiles, puis se spécialisa sur les Dioscoreacées (les ignames), et rédigea une œuvre monumentale qui est toujours utilisée et réimprimée, A dictionary of the economic products of the Malay Peninsula (1935). Il s'intéressa aux plantes cultivées, à leurs origines et à leur histoire, en une approche humaniste faisant un large appel à la nomenclature $(1938,1953)$, ou encore aux causes religieuses de la dispersion des plantes (1946). Comme le souligne Barrau, le « botaniste et humaniste » Burkill fait le lien entre la Botanique économique et l'ethnobotanique naissante :

«Burkill fut un précurseur, un fondateur de l'ethnobotanique moderne; il sut s'affranchir de la sécheresse si longtemps propre aux travaux de botanique 
économique et il aida puissamment l'ethnobotanique à s'affirmer comme discipline

scientifique ». (Barrau 1965 : 221)

Dans sa revue, Chevalier diffuse régulièrement les travaux de Burkill, dans un article spécifique (Burkill 1937) et surtout dans la section « Notes et actualités » sous forme de compte-rendu ou de traductions de chapitres (par exemple Burkill (d'après) 1926, 1936, 1940a et b, ce dernier ayant été traduit et résumé par Haudricourt). Chevalier publie les résultats des recherches internationales, des comptes rendus ou des résumés des livres, ainsi que des articles originaux sur ces ressources commerciales. Il entretient d'ailleurs une correspondance suivie avec beaucoup de ces acteurs ${ }^{36}$.

\section{7, la revue Economic Botany}

En 1947, le Jardin botanique de New York (New York Botanical Garden) lance une nouvelle revue, Economic Botany, créée par H. A. Gleason et E. H. Fulling, qui va en être l'éditeur pendant dix ans. Basé sur l'importance des plantes pour l'homme, ce nouveau journal a été conçu comme un lieu de rencontre entre les botanistes et les autres chercheurs intéressés par les applications économiques et les utilisations industrielles des plantes et de leurs produits (Robbins 1947). Il entend être un organe destiné à combler la relative pauvreté des périodiques d'information dans ce vaste domaine en Amérique, dont le titre choisi « is of relatively minor importance, for it might as well have been titled by some other term (...) ». (Robbins $1947: 4)^{37}$.

2 Un an plus tard, F. Fosberg (1948) définit un très vaste champ de recherche, très éloigné de la botanique économique «classique » qui se contentait de décrire des plantes utiles, et dans lequel l'ethnobotanique n'est considérée que comme l'étude des relations des « hommes primitifs» avec les plantes (p. 6-7). L'auteur insiste très fortement sur la nécessité d'une taxonomie rigoureuse de toutes les plantes considérées, qu'elles soient alimentaires, techniques, cultivées ou sauvages (ce qui est très exactement la recommandation de Bye 1986). Dans son vaste programme, il embrasse la physiologie, les sols, la génétique, la pathologie, et même les valeurs esthétiques ou récréationnelles des aires de conservation de la flore (1948: 13). Il inclut les plantes utiles directement et aussi indirectement, par exemple à travers l'élevage ou la gestion de l'environnement (ce qu'on appelle maintenant les services écosystémiques).

Quarante ans plus tard, G. Wickens, ancien directeur du jardin botanique de Kew, étend considérablement le concept de Forsberg, tout en définissant la botanique économique comme "...the study of the identification, properties, uses, and distribution of economic plants. ", ou encore « ...the study of plants utilized directly or indirectly by Man. » $(1990: 24)$. Il considère que la botanique économique est une approche pratique de l'usage des plantes, avec un champ depuis la connaissance en profondeur des plantes sauvages (c'est pour lui l'ethnobotanique), jusqu'à l'appréciation des nécessités pour la production commerciale ${ }^{38}$ Il inclut donc les plantes cultivées et les plantations forestières. Concernant l'ethnobotanique, il ne la réserve pas seulement aux populations "tribales", mais il propose de ne pas l'étendre aux exploitations commerciales et à d'éventuelle domestication ${ }^{39}$. Toutefois, il rapporte que Barrau travaillant auprès des paysans du sud-est de la France "was happy to regard his studies as ethnobotanical research » (1990: 18). On voit ainsi que la conception de l'ethnobotanique portée dans la revue Economic Botany est assez éloignée de celle prônée par Portères (voir plus bas)! Wickens poursuit son article en présentant les diverses approches 
régionales (Inde, Afrique du Sud, Australie, USA, Grande Bretagne), en commençant par la France et précisément les positions de Roland Portères puis de Jacques Barrau.

\section{L'émergence de l'ethnobotanique}

\section{6, Ethnobotany}

L'« ethnographie botanique ", l'intuition de Alphonse de Rochebrune (1836-1912) en 1879 au Muséum de Paris, est restée sans lendemain. C'est aux États-Unis, 15 ans plus tard, que l'ethnobotanique va naître. Elle est cependant précédée par Aboriginal botany, en 1873-1874, définie par le journaliste et voyageur Stephen Powers (1840-1904).

Plusieurs phrases de Powers méritent d'être citées, parce qu'elles contiennent l'essence de ce qui va se formaliser en ethnobotanique :

"Under it [the word "botany"] are included all the forms of the vegetable world which the aborigines use for medicine, food, textile fabrics, ornaments, etc. .Among savages, of course, there is no systematic classification of botanical knowledge. Every oak, pine, and grass has its separate name ; the Indian never groups individuals together, except occasionally, by adding one of the words cha, doo, popo, com, wi, back, (tree, bush, grass, seed, root, leaf) or something of that sort. But it is not for a moment to be supposed that the Indian is a superficial observer; he takes careful note of the forms and qualities of everything that grows on the face of the earth.» Et plus loin « Nothing escapes him-he has a name for everything ». (Powers 1873 : 373)

Et sa phrase de conclusion à propos du corps humain :

« Although it is not strictly germain to the topic, I may be permitted to state that the Indians have names for all the internal organs of the human body; and their ideas of their functions, and of the operations of medicine, are at least as respectable as those of the Chinese ». (Powers $1873:$ 379)

107 L'histoire de l'ethnobotanique a été maintes fois décrite ${ }^{40}$, depuis ses prémices donc, Aboriginal botany en 1873-1874, jusqu'à Ethnobotany, son baptême et sa définition par le botaniste John Harshberger (1869-1929), en 1896 (Harshberger 1896a).

C'est l'exploration du sud-ouest des États-Unis qui va donner lieu aux premières publications nommées « ethnobotaniques ", toutes réalisées par des anthropologues. La même année que le texte de Harshberger, l'anthropologue Walter Fewkes (1850-1930) publie une étude sur les plantes chez les Hopi qu'il intitule «A contribution to ethnobotany» (1896). Au même moment, son collègue Walter Hough (1859-1935) consacre lui aussi une étude aux Hopi qui concerne les plantes, en se référant pour partie à la publication de Fewkes, mais sans employer le vocable « ethnobotanique » (Hough 1897). Dans l'ensemble, ces publications comportent essentiellement des listes de plantes avec leurs noms et leurs usages. Il en va de même avec des travaux ultérieurs sur la même région (Barrows 1900, Stevenson 1908-1909).

Plus tard, en 1916, ce sera le linguiste John P. Harrington (1884-1961), étudiant tous les aspects de la société Tewa ${ }^{41}$, qui publie une étude ethnobotanique, avec le botaniste Wilfred W. Robbins (1884-1952) et l'anthropologue britannique Barbara Freire-Marreco (1879-1967), une étude qui s'écarte des simples listes et pose des principes ambitieux pour ce domaine de recherche :

«Ethnobotany is virtually a new field of research, a field which, if investigated thoroughly and systematically, will yield results of great value to the ethnologist 
and incidentally also to the botanist. [...] It is a comparatively easy matter for one to collect plants, to procure their names from the Indians, then to send the plants to a botanist for determination, and ultimately to formulate a list of plants and accompanying Indian names, with some notes regarding their medicinal and other uses. Ethnobotanical investigation deserves to be taken more seriously: it should yield more information than this; it should strike deeper into the thoughts and life of the people studied. If we are to learn more of primitive peoples, we must attempt to gain from them their conceptions not of a part but of the entire environment. Ethnobotany is a special line of ethnologic investigation, the results of which must receive consideration in our ultimate analysis ». (Robbins et al. $1916: 1$ )

Le programme de Harshberger s'est conçu à la suite de demande de déterminations botaniques de restes végétaux archéologiques. Il ne l'a cependant pas limité à cet aspect, et l'a élargi jusqu'à concevoir des jardins ethnobotaniques (1896b) ${ }^{42}$ C'était aussi l'archéologie qui avait conduit Rochebrune à penser son « ethnographie botanique ». Plus tard, c'est également pour répondre aux demandes d'identification de matériel végétal par des archéologues que Melvin $R$. Gilmore a créé le laboratoire d'ethnobotanique de l'Université du Michigan en 1932. Il nous semble qu'il s'agit là du premier qui ait porté ce titre; il a été conçu pour être le laboratoire national d'identification du matériel végétal archéologique. Gilmore précise d'ailleurs :

"I very willingly complied with the requests, for I have long held the belief that as careful study should be made of all vegetal remains of prehistoric human cultures as of any other criteria of culture. In my view the development of a people's phytotechnics is fundamental to the development of all their arts of life ». (Gilmore 1932a : 1)

La même année, il expose son point de vue sur l'ethnobotanique, qu'il commence par ces mots très explicites :

"There is one division of ethnological investigation which has ever been sadly neglected. I refer to ethnobotanical inquiry and collection ». (Gilmore 1932b : 320)

Naturaliste et ethnologue, Melvin R. Gilmore (1868-1940), avait dès 1909 présenté sa thèse de Master à l'Université du Nebraska, intitulée «A study in the ethnobotany of the Omaha Indians ». A suivi une grosse étude sur les plantes utilisées dans la vallée du Missouri (Gilmore 1911-1912), dans laquelle il emploie l'expression Ethnic botany, concluant ce paragraphe par la valorisation des savoirs autochtones :

« Besides this body of special plant lore there was also a great deal of knowledge of plants in general and their common uses, their range, habits, and habitat, diffused among the common people. There was also a body of folk sayings and myths alluding to plants commonly known ». (Gilmore 1911-12 : 55-56)

Pour résumer, on peut comparer un peu schématiquement les deux approches. La botanique économique se concentre sur les plantes utiles, et se donne comme projet de reconnaître, identifier et décrire les espèces utilisées par les peuples (pas nécessairement "primitifs ", si l'on en juge par les ouvrages majeurs sur l'Inde ou la Malaisie). Le programme de l'ethnobotanique est tout autre: il s'agit de prendre en compte tous les aspects culturels des relations d'une société avec le monde des plantes (et au départ, des peuples « primitifs » parce qu'ils sont encore en relation étroite avec le monde végétal).

114 Plus tard, Richard E. Schultes (1915-2001), professeur de botanique à Harvard, fera une tentative de synthèse entre l'ethnobotanique (il est considéré aux USA comme « le père de l'ethnobotanique moderne », cf. Prance 2001) et la botanique économique, à la suite de ses recherches sur les plantes à poisons, les plantes médicinales et les plantes 
hallucinogènes d'Amérique latine et plus particulièrement en Amazonie (Schultes 1936, 1979, Vestal \& Schultes 1939) ${ }^{43}$.

Un anthropologue majeur fait une œuvre singulière, sur laquelle nous reviendrons plus loin ; c'est Harold Conklin (1926-2016), que nous citons ici parce que sa thèse consacrée à une population des Philippines ne s'intitule aucunement " ethnobotanique ", mais The relation of Hanunò culture to the plant world (Conklin 1954a). Ce titre n'est pas sans rappeler celui de W. Hough sur les Hopi (1897), mais les deux travaux n'ont en commun que les plantes. Le travail de Conklin repose sur une analyse taxinomique très novatrice, qui va lui permettre de mettre en évidence la conception que les Hanunòo ont du monde des plantes.

\section{4, le JATBA}

116 En France, le saut épistémologique se fera au changement du titulaire de la chaire d'agronomie coloniale : on le sait, c'est Roland Portères qui le réalisera, en prenant la succession de Chevalier en 1948, sans changer le nom de la chaire («tropicale » ne remplacera « coloniale » que dix ans plus tard), mais en modifiant la publication. Sur la suggestion de Chevalier, devenu professeur honoraire, Portères garde partiellement le titre de la RBA mais en intervertissant les mots-clefs (Journal d'agriculture tropicale et de botanique appliquée), et surtout avec une ligne éditoriale totalement différente. Outre Portères, les acteurs du changement sont Jean-François Leroy, alors sous-directeur $\mathrm{du}$ laboratoire et Paul Vayssière, professeur titulaire de la chaire d'entomologie agricole et gestionnaire par intérim de la chaire d'agronomie tropicale à ce moment-là (cf. Hoare $2012 \S \S 42-45)$. C'est alors que le périodique rejoindra les courants internationaux liés aux relations entre les sociétés humaines et les plantes (cf. Bahuchet \& Lizet 2003 pour l'histoire du laboratoire, Bahuchet 2012 pour celle du JATBA).

117 La même année 1954 se tient à Paris le congrès international de botanique, avec une session « ethnobotanique », où sont présents, parmi d'autres, le spécialiste britannique des plantes cultivées J. G. Hawkes, l'Abbé Raponda-Walker ${ }^{44}$, Louis Hédin le co-auteur de l'Homme et les plantes cultivées, et Jacques Rousseau, directeur du jardin botanique de Montréal.

Mais aux côtés de Roland Portères figure André-Georges Haudricourt ${ }^{45}$, ancien vacataire de Chevalier, et à cette époque (1954) linguiste au CNRS (Figure 8). Celui-ci avait rédigé l'Homme et les plantes cultivées dans le laboratoire d'Agronomie coloniale, avec l'agronome Louis Hédin (1904-1982), livre qui paraît en 1943. Chevalier en écrit la préface, et c'est dans la conclusion du livre qu'est introduit en français le terme d'« Ethno-Botanique » $(1943: 203)^{46}$. 
Figure 8 : André-Georges Haudricourt (1911-1996), inspirateur de l'ethnobotanique en France

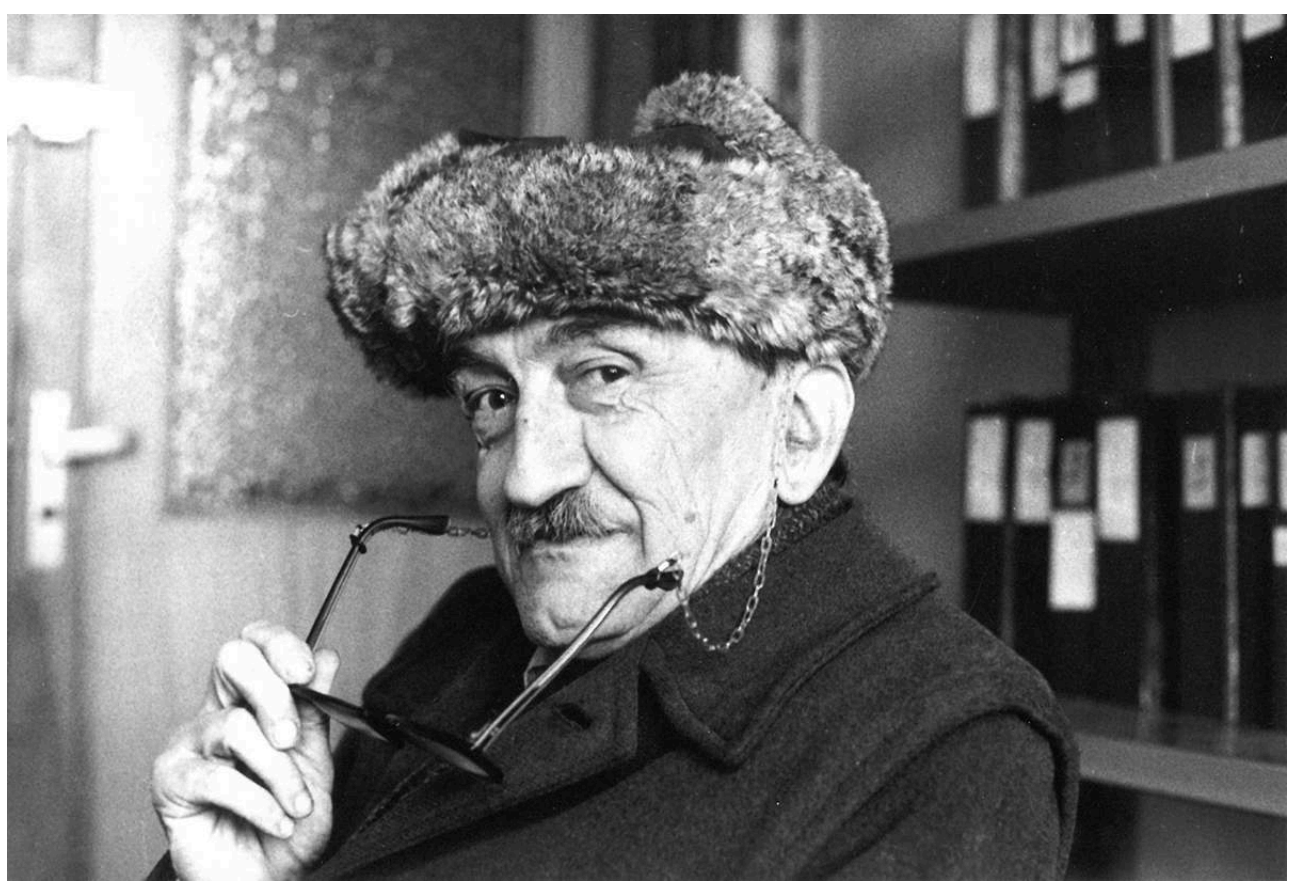

Cliche C. Gaulin, @ archives des collections d'ethnobotanique

119 La notion et le terme d'ethnobotanique sont présents dans le laboratoire dès que Portères en prend la direction, comme en témoignent articles et rapports d'activités publiés dans le JATBA (Portères 1955a, 1955b, 1957) ${ }^{47}$. En 1961, le botaniste québécois Jacques Rousseau (1905-1970) enseigne l'ethnobotanique à la Sorbonne, ce qu'il fait déjà à Montréal depuis très longtemps, suivant la tradition qui s'est construite en Amérique du nord (Rousseau 1961, Rousseau \& Raymond 1945). La même année, et dans le même numéro du JATBA, Portères pose les termes de son projet. On connaît ses déclarations programmatiques : l'ethnobotanique est une science humaine et n'a rien à voir avec la botanique (Portères 1961, 1966) - qui ne sont pas sans rappeler celles de Gilmore en 1932. Enfin en 1963 Portères transforme sa chaire en chaire d'ethnobotanique ${ }^{48}$ (cf. Bahuchet et al. 2019).

120 C'est à la même période, à partir de 1956, que l'agronome Jacques Barrau (1925-1997) va rédiger au laboratoire sa thèse sur Les plantes alimentaires de l'océanie (1962), qui se basait sur plus de 20 ans de séjours en Nouvelle Calédonie et à travers tout le Pacifique. Devenu plus tard sous-directeur du laboratoire d'ethnobotanique, Barrau défendra inlassablement l'ethnobotanique au Muséum et dans le champ intellectuel et universitaire français, et plus largement l'approche écologique en sciences humaines et l'interdisciplinarité ${ }^{49}$ (Barrau 1971, 1974, 1975, 1977 et encore 2000).

\section{Ethnobiologie, ethnoécologie, ethnoscience, ethnosciences...}

121 Au cours de ses séjours en Océanie Jacques Barrau rencontra l'anthropologue Harold Conklin, et à travers lui, les courants scientifiques qui se développent aux Etats-Unis. En 1964-1965, il sera professeur invité à Yale, et à son retour au Muséum, il diffusera 
ces nouveaux domaines, l'écologie culturelle, l'ethnobiologie, l'ethnoécologie et l'ethnoscience (Barrau 1976, 1984).

\section{Cultural ecology}

En étudiant la diversité des cultures de la grande région du sud-ouest des USA, dite Grand Basin, Julian Steward (1902-1972) a pris conscience de l'importance des facteurs écologiques, autant que des éléments sociaux :

"The present analysis of Southwestern society assumes that cultural process, and therefore sound historical reconstruction, can be understood only if due attention is paid to the economic or ecological factors that shape society. This is not a position of extreme economic determinism but rather an enquiry as to the degree and manner in which economic factors have combined with kinship, ceremonialism, inheritance, and the other factors ordinarily stressed, to produce observed social patterns ». (Steward $1937: 88$ )

Il consacre l'année suivante une grande synthèse aux sociétés de cette région, dans laquelle il met en application ses principes d'analyse :

"Analysis of human ecology in the Basin-Plateau area requires consideration first of certain features of the natural landscape or environment; second, of cultural devices by which the environment was exploited; and third, of resulting adaptations of human behavior and institutions ». (Steward $1938: 2$ )

Et plus loin :

«The combined effect of these ecological and social factors produced the observed sociopolitical types, with their varying size, composition, structure, unity, and political controls ». (Steward $1938: 3$ ).

Dans la partie conclusive, "Analysis of data ", il distingue les déterminants écologiques (p. 230), les déterminants sociaux (p. 237) et les formes (patterns) sociales et politiques (p. 239).

Il va affiner sa démarche théorique en dirigeant le Handbook of South American Indians ${ }^{50}$, et tout particulièrement dans le Volume V « The comparative ethnology ", 1949, dont il a rédigé lui-même la partie 4 (South American cultures: an interpretative summary, pp. 669-772). Dans ce travail les paramètres écologiques sont très présents.

Steward va finalement synthétiser et formaliser sa théorie et sa méthodologie dans le livre Theory of culture change. The methodology of multilinear evolution (1955), dont le second chapitre s'ouvre sur l'important The Concept and Method of Cultural Ecology, qui a ensuite été publié isolément (1968). Il explique :

«Cultural ecology differs from human and social ecology in seeking to explain the origin of particular cultural features and patterns which characterize different areas rather than to derive general principles applicable to any culturalenvironmental situation ». (Steward 1955 : 36)

Même si ses conclusions ou ses concepts (comme celui d'adaptation) ont été critiqués, il n'en demeure pas moins que c'est Julian Steward qui ouvre la voie au vaste courant des recherches en «Écologie et sciences humaines " $^{51}$

\section{Ethnobiology}

En 1944, l'ethnobotaniste étatsunien Edward F. Castetter (1896-1978) propose la définition de ethnobiology, comme unissant les approches ethnobotaniques, consacrées 
aux plantes, et ethnozoologiques, quand elles concernent les animaux. Professeur à l'Université du Nouveau Mexique, cela fait déjà une grande décennie qu'il se consacre à l'étude des plantes dans les communautés amérindiennes du sud-ouest des États-Unis, études qu'il publie à partir de 1935 dans une série d'ouvrages intitulés Ethnobiological studies in the American Southwest (par exemple Bell \& Castetter 1941, Castetter 1935, Castetter et al. 1938). La plupart porte sur les usages de diverses plantes mais certaines abordent effectivement aussi le monde animal (Castetter \& Underhill 1935) ou bien l'agriculture (Castetter \& Bell 1942).

130 On verra plus loin comment l'ethnobiology a pris récemment une place considérable dans ce champ particulier de l'anthropologie. À Paris en 1994, pour prendre acte de l'évolution des courants scientifiques outre-Atlantique, le titre du Journal qui était depuis 1977 Journal d'agriculture traditionnelle et de botanique appliquée, travaux d'ethnobotanique et d'ethnozoologie, était modifié JATBA-Revue d'ethnobiologie (cf. Hoare $2012)^{52}$.

\section{Ethnoecology}

Parallèlement à son travail de thèse sur le monde des plantes aux Philippines, 'Hal' Conklin réalise, pour la FAO, une étude très approfondie sur l'agriculture itinérante sur brûlis de la même communauté, dans laquelle il utilise largement le vocabulaire hanunòo (1954b, 1957). C'est dans ce document qu'il utilise le terme d'ethnoécologie (An ethnoecological approach to shifting agriculture) - qu'il pratique avec brio et d'une manière très convaincante, mais qu'il ne définit d'ailleurs pas.

Conklin était autant linguiste qu'anthropologue, et il accorde une importance considérable au vocabulaire employé par les sociétés qu'il étudie (Conklin 1953, 1955, $1986,2012)^{53}$. De ce fait, son ethnoecology se caractérise par une égale importance aux données lexicales et aux observations des pratiques. Il associe les techniques en relation avec les caractères de l'environnement, et les connaissances traditionnelles le concernant, telles que véhiculées par la langue.

133 Sa démarche a fait durablement école. Quelques étapes: en 1984, l'ethnobiologiste Darrell Posey, à partir de ses recherches très complètes sur les Kayapo du Brésil (et notamment ses travaux d'ethnoentomologie, voir plus loin) expose l'importance de l'approche ethnoécologique pour le développement en Amazonie (Posey et al. 1984). En 1992, l'écologue mexicain Victor M. Toledo crée la revue Etnoecológica, dans laquelle il propose une définition de l'ethnoécologie et un programme de recherche appliquée (Toledo 1992 $2^{54}$ ).

134 Enfin, parmi les développements de l'ethnoécologie, nous aimerions en citer deux qui nous paraissent exemplaires et novateurs: en tout premier lieu, l'étude d'ethnobotanique menée par W. Balée chez les Ka'apor d'Amazonie, qui conduit l'auteur à promouvoir les études d'écologie historique à partir des pratiques et savoirs locaux (Balée 1994). D'autre part, l'extension de l'ethnoécologie au-delà des plantes et des animaux, conduisant à une ethnoécologie du paysage (Johnson \& Hunn 2012).

\section{Ethnoscience}

Cette même période des années 1950, décidément très riche pour notre domaine, voit apparaitre aux USA une nouvelle formule: ethnoscience (quelquefois dite aussi folk 
science, cf. Barrau 198455). C'est à l'anthropologue George P. Murdock (1897-198556) que l'on doit son invention.

Dès les années 1930, Murdock met en place un projet pour développer une méthodologie d'analyse afin de comparer les cultures du monde, dans le cadre de l'Institute of Human Relations à Yale. Ce programme, le Cross-cultural survey, est conçu pour tester quantitativement des théories scientifiques sur la culture et l'organisation sociale (Murdock 1940, May 1971). Pour cela il a fallu sélectionner un échantillonnage représentatif de différentes cultures du monde (Outline of world cultures, Murdock 1954) et composer un système standard de classification du matériel ethnographique, c'est le Outline of cultural materials ( $1^{\mathrm{e}}$ éd. 1938, révisé régulièrement, $4^{\mathrm{e}}$ éd. Murdock et al. 1965). Ce programme d'envergure mondial se concrétise à partir de 1949-1950 dans l'établissement d'une base de données, qui se fonde sur le codage de très nombreuses publications anthropologiques : Human Relations Area Files, HRAF (Ember 1988).

Dans l'index de la $3^{e}$ édition du Outline of cultural materials, en 1950, apparaît le terme ethnoscience, forgé par Murdock, pour une catégorie spécifique de comportements symboliques, dans la rubrique intitulée «Ideas about nature and man » (\$ 82). La rubrique elle-même est décomposée en de nombreux sous-thèmes: "ethnometeorology, ethnophysics, ethnogeography, ethnobotany, ethnozoology, ethnoanatomy, ethnophysiology, ethnopsychology, ethnosociology. ». Par exemple, ethnobotanique est explicitée ainsi ${ }^{57}$ :

« 824 ethnobotany - notions about plants in general; ideas about particular plants

(...); cultural uses of plants; native terms for plants; knowledge of poisonous plants;

associated behavior patterns; etc. ». (Murdock et al. 1965 :128-131)

C'est précisément ce que Friedberg (2005) visait dans son commentaire railleur sur les ethno "machins ", dénonçant le «saucissonnage » de ce qui au contraire relève du même comportement cognitif envers le monde.

Paradoxalement, c'est en critiquant Murdock, que des anthropologues vont s'emparer de l'ethnoscience pour en étendre considérablement l'usage, jusqu'à fonder une «nouvelle ethnographie ».

\section{Ethnoscience et « Nouvelle Ethnographie » ${ }^{58}$}

En 1962, l'anthropologue et linguiste Charles O. Frake, qui comme Conklin travaille aux Philippines notamment sur l'agriculture sur brûlis mais aussi sur les maladies, pose le principe de prendre en compte le monde cognitif des membres des populations que l'ethnographe prétend décrire, car :

«It must discover those features of objects and events which they regard as significant for defining concepts, formulating propositions, and making decisions » (Frake 1962:54)

Et il précise que les unités que l'observateur segmente et organise, doivent l'être selon les contrastes inhérents aux données elles-mêmes et non selon des catégories posées à priori, ce pour quoi il prend l'exemple de l'étude de Conklin sur le monde végétale hanunòo. Il poursuit :

"An ethnographer, then, cannot be satisfied with a mere cataloguing of the components of a cultural ecosystem according to the categories of Western science. He must also describe the environment as the people themselves construe it according to the categories of their ethnoscience $»^{59}$. (Frake $1962: 55$ ) 

invisible (Revel 1990a, 1990b).

\section{Les plantes} (Brown 1977, 1979).

En 1962 aussi, la parution du livre La pensée sauvage de Claude Lévi-Strauss diffuse en France «la science du concret» (titre du premier chapitre) révélée par les travaux anthropologiques notamment étatsuniens, en premier lieu ceux de Conklin.

L'anthropologue William C. Sturtevant (1926-2007) formalise les propositions de Frake et construit un véritable programme de recherche, en se basant sur de nombreux exemples dans différents domaines de l'anthropologie. En effet, pour Sturtevant, «It is claimed that ethnoscience is a general ethnographic method» (Sturtevant 1964: 123). Considérant qu'un système de connaissances et de cognition est typique d'une culture donnée, autrement dit que chaque culture a sa manière particulière de classifier son univers matériel et social (pp. 99-100), il propose donc d'appliquer cette méthode bien au-delà du monde des plantes ou des animaux, dont il donne des exemples, tels que les terminologies de parenté, les noms de couleurs, les sens, les «types sociaux» ... Nous retenons aussi de cet article programmatique cette jolie définition de la classification comme une « réduction du chaos » $(1964: 100)^{60}$ !

L'ethnolinguiste Nicole Revel a appliqué cette démarche d'ethnoscience globale dans l'étude majeure d'une société des Philippines, celles des Palawan, à partir d'une ethnographie et d'une lexicographie minutieuses, prenant en compte tant les éléments du monde vivant (plantes et animaux) que le temps, le travail, les outils ou le monde

En France, le terme qui est employé est ethnosciences (au pluriel). Cela marquait une opposition entre une théorie globalisante, qui conduit à une anthropologie cognitive et plus tard à une psychologie cognitive, au risque d'écarter les aspects qualitatifs de la vie quotidienne, objets de la vieille ethnographie. Au contraire l'ethnobotanique ou l'ethnozoologie pratiquées en France intègrent en effet les conceptions endogènes du monde des plantes ou des animaux, mais en y intégrant leur place dans l'ensemble de la société ; elles reposent sur une conception holistique de la société ${ }^{61}$. Et dans ce cas, « les ethnosciences » correspondent plus à des méthodes d'enquêtes de terrain adaptées aux spécificités des différents domaines naturalistes qu'à un principe théorique général (voir Bouquiaux \& Thomas 1987).

\section{Taxinomies et classifications}

Dans le domaine spécifique du monde vivant, l'application assez stricte de cette notion d'ethnoscience va entraîner des travaux spécialisés sur les classifications des plantes. L'ouvrage majeur qui initie ce mouvement est celui réalisé par un anthropologue avec une équipe de botanistes sur une communauté du Mexique, les Tzeltal (Berlin et al. $1966,1968,1974)^{62}$. Il est basé sur un recueil méticuleux de toutes les plantes connues de cette communauté, de la terminologie employée et des critères de distinction appliqués par les Tzeltal eux-mêmes. L'analyse de ces données conduisit les auteurs à proposer une classification, au sens linnéen du terme, à plusieurs niveaux hiérarchiques, essentiellement basée sur la forme linguistique des noms ${ }^{63}$.

Cette approche théorique a conduit à des hypothèses sur l'universalité de ces principes de classification, d'abord sur les formes de vie des plantes, puis sur celles des animaux 

qui forge le vocable ethnozoology ${ }^{66}$, il faut attendre un demi-siècle pour voir des recherches majeures menées dans ce domaine, celles de l'anthropologue et naturaliste britannique Ralph Bulmer (1928-1988) ${ }^{67}$ qui se consacre à l'étude des taxonomies zoologiques traditionnelles dans les hautes terres de la Nouvelle Guinée, tout particulièrement chez les Kalam. Il leur consacre une impressionnante série d'articles sur les grenouilles, les reptiles, les mammifères, les poissons... (Bulmer 1967, 1968, 1974a, Bulmer et al. 1975, Bulmer \& Tyler 1968), travaux qui culminent par un chef d'œuvre rédigé avec son assistant de recherche kalam, Birds of My Kalam Country 
(Majnep \& Bulmer 1977). Dans un article paru dans le JATBA, R. Bulmer rapporte sa démarche et explicite sa méthode de terrain (Bulmer 1974b).

Roy Ellen se situe dans la même ligne, pour une île d'Indonésie (Ellen et al. 1977). Comme le fait à la même période Eugen Hunn au Mexique, les deux chercheurs analysent les catégories animales et les classifications en les replaçant dans la culture locale (Ellen 1993, Hunn 1977). Il est intéressant de relever que ces deux auteurs n'emploient pas le terme d'ethnozoologie pour qualifier leur démarche. Hunn préfère folk-zoology, comme un peu plus tard l'anthropologue québécois Daniel Clément parle directement de « zoologie des Montagnais ", réfutant qu'elle se distingue de la science « occidentale» (Clément 1995).

L'anthropologue Darrell A. Posey (1947-2001) quant à lui, a consacré des recherches très détaillées sur l'ethnoentomologie d'une communauté du Brésil, les Kayapo, en particulier sur le rôle des hyménoptères qu'il met en relation avec l'organisation sociale de ce peuple (Posey 1981, 1982). Il en tire des principes méthodologiques susceptibles de guider les recherches anthropologiques, rejoignant ainsi les propositions de Sturtevant (1964).

$156 \mathrm{Au}$ Muséum, Portères avait étendu son laboratoire à l'ethnozoologie en faisant appel à Raymond Pujol en 1966 (Figure 9); celui-ci, ethnoentomologiste œuvrant particulièrement en Afrique centrale, enseignera cette spécialité et s'entourera de nombreux étudiants qu'il va notamment former à l'enquête sur le terrain (cf. Pujol 1969-70, Pujol \& Carbone 1990).

Figure 9 : Raymond Pujol (1927), introducteur de l'ethnozoologie au Muséum

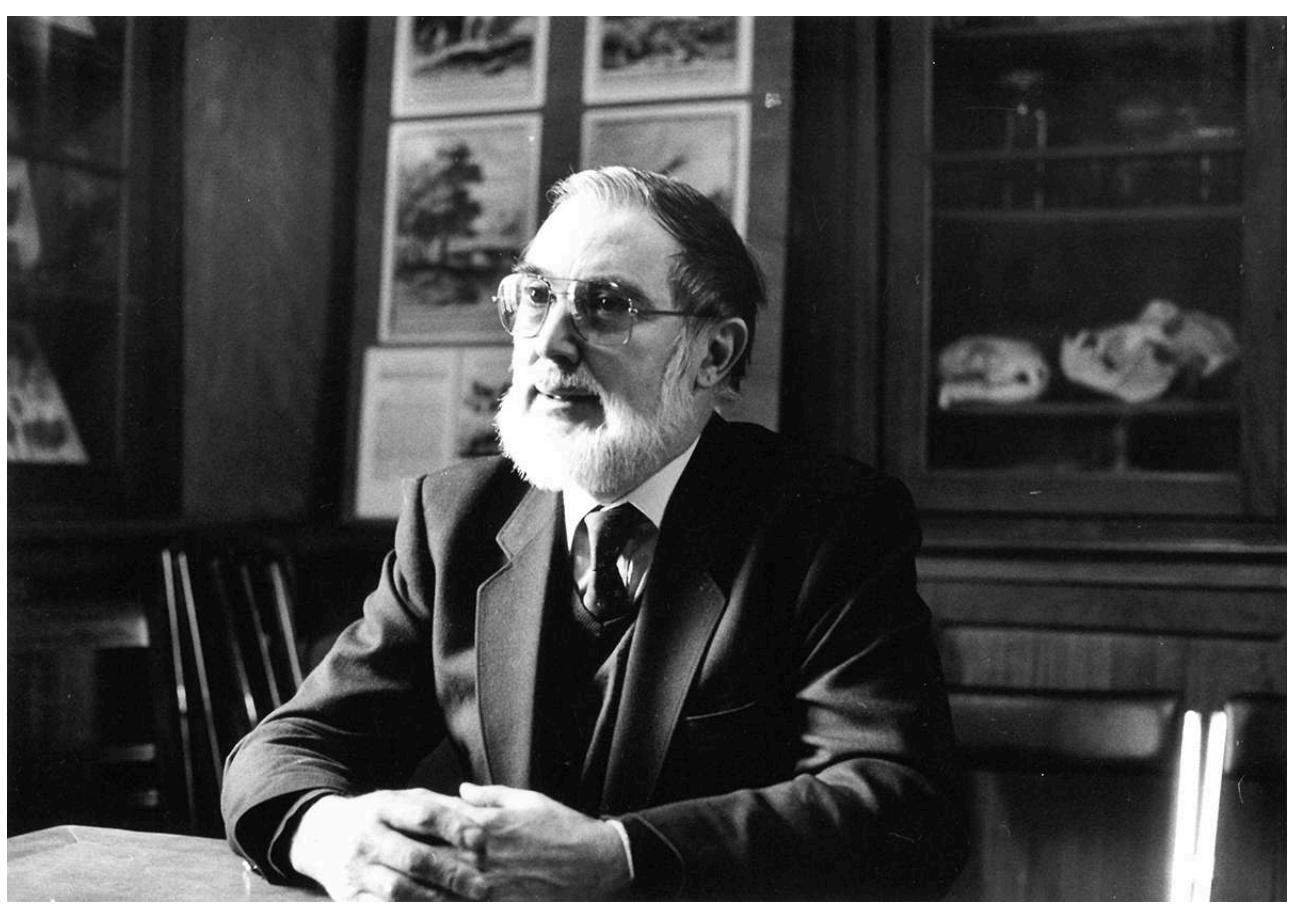

Cliché C. Gaulin, @ archives des collections d'ethnobotanique 


\section{Années 1980 : les TEK, Traditional Ecological Knowledge}

157 À la fin des années 1970, les recherches de l'écologiste marin Robert E. Johannes ${ }^{68}$ (1936-2002) sur la gestion des pêches en Océanie notamment dans les récifs coralliens, le conduisent à porter une attention de plus en plus fine aux pratiques des pêcheurs locaux, à leurs savoirs naturalistes, et à leur gestion des ressources aquatiques (Johannes 1978, 1981a et b, Ruddle et al. 1992). Son approche pragmatique a beaucoup d'influence; le mouvement prend de l'ampleur pour associer les communautés locales à la gestion des ressources (Inglis 1993, Johannes 1989). Ces réflexions se déroulent dans le contexte de la préparation du sommet de la terre à Rio (tenu en 1992), et de fait, les savoirs traditionnels sont pris en compte dans plusieurs des articles de la Convention de la Diversité Biologique qui est promulguée cette même année ${ }^{69}$. Évidemment le terme d'ethnobiologie, très académique, n'est pas repris, mais les idées qu'il comporte le sont (en particulier dans les articles $8 \mathrm{j}$ et $10 \mathrm{c}$ ). Plusieurs publications discutent de la contribution des connaissances locales pour un meilleur développement écologique (Moller et al. 2004, Roué \& Nakashima 2002, Sillitoe 1998). Un document pratique a été publié au Canada (Grenier 1998).

Plus récemment, $\mathrm{V}$. Toledo reprend sa définition de l'ethnoécologie en l'élargissant, et surtout en insistant sur l'importance des savoirs traditionnels (Toledo \& BarreraBassols 2008), en même temps que s'impose pour les scientifiques académiques la nécessité de faire « dialoguer » toutes les formes de savoirs (cf. Argueta et al. 2011).

\section{Le retour de l'ethnobiology}

À la fin $\mathrm{du} \mathrm{xx}^{\mathrm{e}}$ siècle, le terme ethnobiologie supplante quasi-complètement celui d'ethnoscience, et les travaux sur les classifications se font rares, tout comme la quête des universaux. Relevons toutefois l'ouvrage majeur de Philippe Descola, qui étend au monde vivant l'analyse structuraliste de C. Lévi-Strauss, pour mettre en évidence des universaux dans les rapports à la nature et les conceptions, ce qui lui permet de dégager un nombre réduit d'ontologies (Descola 2005).

160 L'ethnobiologie se développe à travers la création de deux sociétés majeures, la Society for Ethnobiology en 1977 (qui publie le Journal of ethnobiology), l'International Society for Ethnobiology (ISE) en 1988, et la fondation de plusieurs périodiques: Journal of ethnobiology en 1981, Etnobiología au Mexique (2001), Journal of ethnobiology and ethnomedecine (2005).

161 Dans le domaine des ouvrages, on notera la publication dirigée par Roy Ellen d'un numéro spécial du Journal of the Royal Anthropological Institute (JRAI) en 2006, et un très gros manuel dirigé par E. Anderson et al. en 2011, intitulé sobrement Ethnobiology.

Les questions d'éthique portant sur les savoirs locaux et les droits de propriété intellectuelle qui doivent leur être associés s'imposent désormais, en réaction à plusieurs cas de «biopiraterie» portant sur des plantes médicinales (cf. Posey \& Dutfield 1996). Ainsi au cours du premier colloque de l'ISE en 1988, fut proclamée la "Déclaration de Belèm», qui insiste sur la reconnaissance du droit des peuples autochtones sur leurs savoirs locaux. Cette déclaration a été révisée 30 ans après, avec la contribution de représentants des communautés autochtones, et surtout la Société a publié un code éthique en 2006, révisé en $2008^{70}$. 
De la même manière, la $10^{e}$ Conférence des Parties de la Convention sur la diversité biologique a adopté un code de conduite éthique: "Code de conduite éthique Tkarihwaié:ri propre à assurer le respect du patrimoine culturel et intellectuel des communautés autochtones et locales » (décision X/42; CDB 2012).

En Amérique latine l'Asociación Etnobiológica Mexicana et la Sociedad latinoamericana de Etnobiología (SOLAE) ont également rédigé, discuté et finalement approuvé lors de plusieurs congrès de la SOLAE un code éthique ${ }^{71}$, publié en 2016 dans la revue Etnobiología (supplément du volume 14, 2016).

\section{Conclusion}

Cette année 2021 voit le centenaire de la Revue de Botanique appliquée. Mais c'est aussi celle du $40^{\mathrm{e}}$ anniversaire du Journal of ethnobiology (Lepofsky et al. 2021).

Eugene Hunn (2007) avait reconnu quatre phases dans l'évolution de l'ethnobiologie ${ }^{72}$ : la phase I, avant la lettre en quelque sorte, qu'on pourrait dire celle des plantes utiles; la phase II, la période de l'anthropologie cognitive ; la phase III qui comprend savoirs, pratiques et écologie, et la phase IV qui intègre «les droits des peuples indigènes à contrôler leur propre savoir traditionnel ».

167 Une cinquième phase a été proposée, qui demande de dépasser les frontières disciplinaires académiques, afin d'affronter les problèmes résultant des crises environnementales et culturelles (Wolverton 2013). Dans le numéro anniversaire du Journal of Ethnobiology, un grand nombre d'ethnobiologistes appelle à une phase VI, associant chercheurs et praticiens, pour combattre toutes les formes d'oppression, de racisme, de colonialisme, notamment dans les institutions et dans les pratiques de recherche (McAlvay et al. 2021).

168 On peut aisément retrouver ces diverses phases dans l'évolution de nos trois journaux. La RBA puis le jeune JATBA relèvent essentiellement de la phase I (les plantes utiles). Cependant dans ces deux périodiques successifs, les articles sur les pratiques agricoles sont présents dès le début, conformément d'ailleurs à leurs titres où figure explicitement le mot agriculture, avec divers qualificatifs (coloniale, tropicale, traditionnelle). Dès le lancement du JATBA, des articles sur les pratiques et les savoirs concernant les écosystèmes sont présents (qui correspondent à la phase III de Hunn). Inversement, les travaux abordant les classifications sont publiés à partie des années 1970 (c'est la phase II de Hunn). Dans notre cas, phases II et III s'interpénètrent, comme les recherches d'ailleurs, car une approche ne remplace pas une autre, elles s'ajoutent et se fertilisent mutuellement.

169 Notre Revue d'Ethnoécologie poursuit le mouvement, en accueillant des travaux relevant des phases contemporaines, mais aussi des précédentes! 


\section{BIBLIOGRAPHIE}

Anderson E.N., Pearsall D., Hunn E. \& Turner N. (Ed.) 2011 - Ethnobiology. John Wiley \& Sons, $399 \mathrm{p}$.

Arber A. 1912 - Herbals: their origin and evolution. A chapter in the history of botany, 1470-1670 (facsimile edition). Glastonbury, The Lost Library, $253 \mathrm{p}$.

Archer T.C. 1853 - Popular Economic Botany ; or description of the botanical and commercial characters. London, Reeve and Co, 359 p.

Argueta Villamar A., Corona-M E. \& Hersch P. (Ed.) 2011 - Saberes colectivos y diálogo de saberes en México. Cuernavaca, UNAM, Centro Regional de Investigaciones Multidisciplinarias, 574 p.

Aymonin G.G. 1967 - Le Professeur Henri Humbert. L'Homme, l'Explorateur, le Savant. Bulletin de la Société botanique de France 114 (9) : 453-462.

Bahuchet S. 1985 - Les Pygmées Aka et la forêt centrafricaine, ethnologie écologique. Paris, SELAF, $638 \mathrm{p}$.

Bahuchet S. 2012 - Du JATBA-Revue d'ethnobiologie à la Revue d'ethnoécologie. Revue d'ethnoécologie 1 [en ligne] doi.org/10.4000/ethnoecologie.689

Bahuchet S. 2018 - Claudine Friedberg (1933-2018). De l'ethnobotanique à l'anthropologie. Revue d'ethnoécologie 14 [en ligne] doi.org/10.4000/ethnoecologie.3798

Bahuchet S., Blanc J., Hoare C., Juraver S., Kourdourli M. \& Pennec F. 2019 - Des hommes et des plantes : les collections d'ethnobotanique du Muséum, état des lieux et projet. Revue d'ethnoécologie 16 [en ligne] doi.org/10.4000/ethnoecologie.5786

Bahuchet S. \& Lizet B. 2003 - L'ethnobotanique au Muséum national d'histoire naturelle. Les hommes, les idées, les structures. In : Lieutaghi P. \& Musset D., Plantes, sociétés, savoirs, symboles. Matériaux pour une ethnobotanique européenne, Musée-conservatoire de Salagon et Les Alpes de lumière ; «les cahiers de Salagon » 8, Mane : 15-32.

Balée W. 1994 - Footprints of the forest: Ka'apor ethnobotany - The historical ecology of plant utilization by an Amazonian people. New York, Colombia University Press, 396 p.

Barrau J. 1962 - Les plantes alimentaires de l'Océanie. Origines, distribution et usages. Marseille, Faculté des sciences, $276 \mathrm{p}$.

Barrau J. 1965 - Isaac Henri Burkill (1870-1965). JATBA 12 (4-5) : 221-223.

Barrau J. 1971 - L'Ethnobotanique, au carrefour des sciences naturelles et des sciences humaines. Bulletin de la Société botanique de France 118 : 237-248.

Barrau J. 1973 - Plantes et comportement des hommes qui les cultivent. L'œuvre ethnobiologique d'André Haudricourt. La Pensée 171 : 37-46.

Barrau J. 1974 - Ecosystèmes, civilisations et sociétés humaines : Le point de vue d'un naturaliste. Informations sur les sciences sociales 14 (1) : 21-34.

Barrau J. 1975 - Ecologie. In : Cresswell R. (Ed.), Eléments d'ethnologie. 2. Six approches. Paris, Armand Colin : 7-43.

Barrau J. 1976 - Ethnobiologie. In : Cresswell R. \& Godelier M. (éds) Outils d'enquête et d'analyse anthropologiques. Maspéro, Paris : 73-83 
Barrau J. 1977 - Histoire naturelle et anthropologie. L'Espace géographique 3 : 203-209.

Barrau J. 1984 - Ethnoscience. In : Encyclopoaedia Universalis : 482-484.

Barrau J. 2000 - L'homme comme objet d'histoire naturelle. JATBA, 42 (1) : 33-48. doi.org/10.3406/ jatba.2000.3727

Barrows D.P. 1900 - The ethno-botany of the Coahuilla Indians of Southern California. Chicago, University of Chicago Press, $82 \mathrm{p}$.

Bell W.H. \& Castetter E.F. 1941 - The Utilization of Yucca, Sotol, and Beargrass by the Aborigines of the American Southwest. University of New Mexico biological series, v. 5, no. 5, University of New Mexico bulletin, whole no. 372, Ethnobiological studies in the American Southwest 7 5, 5

Berlin B. 1992 - Ethnobiological classification. Principles of categorization of plants and animals in traditional societies. Princeton, Princeton University Press, $336 \mathrm{p}$.

Berlin B., Breedlove D.E. \& Raven P.H. 1966 - Folk taxonomies and biological classification. Science 154 (3746) : 273-275.

Berlin B., Breedlove D.E. \& Raven P.H. 1968 - Covert categories and folk taxonomies. American Anthropologist 70 (2) : 290-299.

Berlin B., Breedlove D.E. \& Raven P.H. 1974 - Principles of Tzeltal plant classification. An introduction to the botanical ethnography of a Mayan-speaking people of highland Chiapas. New York, Academic Press, $660 \mathrm{p}$.

Berlin B. \& Kay P. 1969 - Basic Color Terms: Their Universality and Evolution. Berkeley, Univ. California Press, $\mathrm{xi}+178 \mathrm{p}$.

Bois D. 1927-1937 - Les plantes alimentaires chez tous les peuples et à travers les âges. Histoire, utilisation, culture. Paris, Lechevalier, 4 volumes.

Bonneuil C. 1996 - Auguste Chevalier, savant colonial. Entre science et Empire, entre botanique et agronomie. In : Petitjean P. (Ed.), Les sciences coloniales. Figures et institutions Paris, Orstom : 15-36.

Bonneuil C. 1999 - Le Muséum national d'histoire naturelle et l'expansion coloniale de la Troisième République (1870-1914). Revue française d'histoire d'outre-Mer 322-323 : 143-169.

Bonneuil C. \& Kleiche M. 1993 - Du jardin d'essais colonial à la station expérimentale 1880-1930 : éléments pour une histoire du CIRAD. Paris, Cirad, $107 \mathrm{p}$.

Bouquiaux L. \& Thomas J.M.C. (Ed.) 1987 - Enquête et description des langues à tradition orale. Vol. I : L'enquête de terrain et l'analyse grammaticale. Vol. III : Approche thématique (questionnaires techniques et guides thématiques). Paris, SELAF : 1-258 (I), 577-950 (III).

Brown C.H. 1977 - Folk botanical life-forms: their universality and growth. American Anthropologist 79 (2) : 317-342.

Brown C.H. 1979 - Folk Zoological Life-Forms: Their Universality and Growth. American Anthropologist 81 (4) : 791-817.

Brunschwig H. 1959 - Le parti colonial français. Revue française d'histoire d'outre-mer 46 (162) : 49-83.

Bulmer R. 1967 - Why is the cassowary not a bird? A problem of zoological taxonomy among the Karam of the New Guinea Highlands. Man 2 (1) : 5-25.

Bulmer R. 1968 - Worms that croak and other mysteries of Karam natural history. Mankind. The Australian Journal of Anthropology 6 (12) : 621-639. 
Bulmer R.N.H. 1974a - Folk biology in the New Guinea Highlands. Social Science Information 13 $(4-5): 9-28$.

Bulmer R.N.H. 1974b - Memoirs of the small game hunter: on the track of unknown animal categories in New Guinea. JATBA 21 (4) : 79-99.

Bulmer R.N., Menzies J. \& Parker F. 1975 - Kalam classification of reptiles and fishes. The Journal of the Polynesian Society 84 (3) : 267-308.

Bulmer R.N. \& Tyler M.J. 1968 - Karam classification of frogs. The Journal of the Polynesian Society 77 (4) : 333-385.

Bureau E. 1901 - Notice nécrologie de Maxime Cornu. Nouvelles archives du Muséum 4 (3) : XIX-

XXIX.

Burkill I.H. 1935 - A dictionary of the economic products of the Malay Peninsula. London, Crown agents for the colonies, 2 vol., $x i+2402$ p.

Burkill I.H. 1937 - Les origines et la diversité des races cultivées de Sorgho. RBA 17 (191) : 485-495.

Burkill I.H. 1938 - The contact of the Portuguese with African food-plants which gave words such as 'yam' to European languages. Proceedings of the Linnean Society of London 150 (2) : 84-95.

Burkill I.H. 1946 - On the dispersal of the plants most intimate to Buddhism. Journal of the Arnold Arboretum 27 (4) : 327-339.

Burkill I.H. 1953 - The Hooker Lecture: Habits of Man and the Origins of the Cultivated Plants of the Old World. Proceedings of the Linnean Society of London 164 (1) : 12-42.

Burkill I.H. (d'après) 1926 - Origine de quelques espèces d'Ignames. RBA VI (59) : 444-445.

Burkill I.H. (d'après) 1936 - Culture et usages du Riz en Malaisie. RBA XVI $(174,175,176,177)$ :

130-138, 223-230, 301-307, 382-385.

Burkill I.H. (d'après) 1940a - L'origine des cannes à sucre. RBA XX (221) : 50-55.

Burkill I.H. (d'après) 1940b - Les ignames du Congo belge. RBA XX (228-229) : 616-625.

Bye R.A. 1986 - Voucher specimens in ethnobiological studies and publications. Journal of

Ethnobiology 6 (1) : 1-8.

Candolle A. de 1883 - Origine des plantes cultivées. Paris, Baillière et Cie, 380 p.

Candolle A.P. de 1813 - Théorie élémentaire de la botanique. Paris, Déterville, 527 p.

Candolle A.P. de 1816 - Essai sur les propriétés médicales des plantes, comparées avec leurs formes extérieures et leur classification naturelle. Paris, Chez Crochard, 397 p.

Capus G. \& Bois D. 1912 - Les produits coloniaux : origine, production, commerce. Paris, Armand Colin, $\mathrm{XVI}+687 \mathrm{p}$.

Castetter E.F. 1935 - Uncultivated native plants uses as sources of food. University of New Mexico biological series, v. 4, no. 1, University of New Mexico bulletin, whole no. 266, Ethnobiological studies in the American Southwest, 14,1

Castetter E.F. 1944 - The domain of ethnobiology. The American Naturalist 78 (775) : 158-170.

Castetter E.F. \& Bell W.H. 1942 - Pima and Papago Indian Agriculture. Albuquerque, University of New Mexico, $\mathrm{xv}+245$ p. (Inter-Americana Studies ; I).

Castetter E.F., Bell W.H. \& Grove A.R. 1938 - The early utilization and the distribution of agave in the American southwest. Univ. New Mex. Bull., Ethnobiological studies VI, 92 p. 
Castetter E.F. \& Underhill R.M. 1935 - The ethnobiology of the Papago Indians. Univ. New Mex. Bull., Ethnobiological studies II, 84 p.

CDB 2012 - Tkarihwaiéri. Code de conduite éthique propre à assurer le respect du patrimoine culturel et intellectuel des communautés autochtones et locales présentant un intérêt pour la conservation et l'utilisation durable de la diversité biologique. Montréal, Secrétariat de la CDB, 16 p.

Center for Economic Botany s.d. - Plants+People. An exhibition of items from Economic Botany Collections in Museum $N^{\circ} 1$. Kew, The Royal Botanic Gardens, 23 p.

Chambre syndicale du commerce colonial 1894 - Notice sur l'Union coloniale française. Paris, Challamel, $7 \mathrm{p}$.

Chevalier A. 1901 - Un ancêtre présumé du melon cultivé (Cucumis melo L.). Bulletin du Muséum 7 (1) : 284-287.

Chevalier A. 1923 - Notice sur les titres et travaux scientifiques. Paris, Lechevallier, 168 p.

Chevalier A. 1930 - L'agronomie coloniale et le Muséum national d'histoire naturelle (premières conférences du cours sur les productions végétales et l'agronomie coloniale). Paris, Laboratoire d'agronomie coloniale, $128 \mathrm{p}$.

Chevalier A. 1932 - Les Productions végétales du Sahara et de ses confins Nord et Sud. Passé Présent - Avenir. RBA 12 (133-134) : 669-924.

Chevalier A. 1934a - Les rapports des Noirs avec la nature. Sur l'utilisation par les indigènes du Gabon d'une fougère pour piégeage et d'un champignon pour la fabrication des ceintures de parure. Journal des Africanistes 4 (1) : 123-128.

Chevalier A. 1934b - Michel Adanson : voyageur, naturaliste et philosophe. Paris, Larose, 174 p.

Chevalier A. 1934c - Nécrologie : Professeur Henri Lecomte (1856-1934). Revue de botanique appliquée et d'agriculture coloniale 14 (160) : 1070-1076.

Chevalier A. 1935a - Le tricentenaire de la fondation du Jardin des Plantes et le rôle du Muséum en agronomie coloniale. RBA $166: 1-26$.

Chevalier A. 1935b - Identification du Champignon employé en Afrique équatoriale pour la confection de ceintures de parure. Journal des Africanistes 5 (2) : 247-249.

Chevalier A. 1935c - Guy-Crescent Fagon : protecteur de la botanique et les genres qui lui ont été dédiés. Archives du Muséum national d'histoire naturelle, série 6, 12 : 649-664.

Chevalier A. 1937a - Rapport préliminaire, IV ${ }^{\mathrm{e}}$ section Botanique pure et appliquée. In : Congrès de la recherche scientifique dans les territoires d'outre-mer, Paris (tiré à part), $10 \mathrm{p}$.

Chevalier A. 1937b - Les plantes magiques cultivées par les Noirs d'Afrique et leur origine. Journal des Africanistes : 93-105.

Chevalier A. 1943 - Historique de la Revue de Botanique Appliquée et d'Agriculture tropicale. Volonté d'en continuer la publication. RBA 23 (257-259) : 1-6.

Clément D. 1995 - La zoologie des Montagnais. Paris, Peeters/Selaf, 569 p.

Clément D. 1998 - Les fondements historiques de l'ethnobiologie (1860-1899). Anthropologica XL : 109-128.

Conklin H.C. 1953 - Hanunòo-English vocabulary. Los Angeles, University of California Press, 290 p. (Publ. Ling. ; 9) 
Conklin H.C. 1954a - The relation of Hanunò culture to the plant world. Thèse. New Haven, Yale University, $471 \mathrm{p}$.

Conklin H.C. 1954b - An ethnoecological approach to shifting agriculture. Transactions of the New York Academy of Sciences 17 (2) : 133-142.

Conklin H.C. 1955 - Hanunòo color categories. Southwestern journal of anthropology 11 (4) : 339-344.

Conklin H.C. 1957 - Hanunòo agriculture. A report on an integral system of shifting cultivation in the Philippines. Rome, FAO, 210 p. (FAO Forestry Development Paper ; 12).

Conklin H.C. 1986 - Des orientements, des vents, des riz... pour une étude lexicologique des savoirs traditionnels. JATBA XXXIII : 3-10.

Conklin H.C. 1998 - Language, culture, and environment: My Early Years. Annual review of anthropology 27 (1) : xiii-xxx.

Conklin H.C. 2012[1962] - Lexicographical treatment of folk taxonomies. In : Joshua A.F. (Ed.) Readings in the Sociology of Language. De Gruyter Mouton : 414-433.

Cornish C. 2013 - Curating Science in an Age of Empire: Kew's Museum of Economic Botany. PhD Thesis, Royal Holloway, University of London.

Cornish C. \& Nesbitt M. 2014 - Historical perspectives on Western ethnobotanical collections. In : Salick J., Konchar K. \& Nesbitt M. (Ed.) Curating biocultural collections. A handbook. Kew, Royal Botanic Gardens : 271-293.

D'Ambrosio U. 2014 - Theoretical reflections on ethnobiology in the third millennium. Contributions to Science : 49-64.

Décret 1793 - Décret de la Convention nationale, du 10 juin 1793, l'an second de la république Françoise, Relatif à l'organisation du Jardin national des Plantes \& du Cabinet d'Histoire naturelle, sous le nom de Muséum d'Histoire naturelle. Paris, Imprimerie nationale, $n^{\circ} 1020,7 \mathrm{p}$.

Descola P. 2005 - Par-delà nature et culture. Paris, Gallimard, 624 p.

Dournes J. 1968 - Bois-Bambou (köyau-ale), aspect végétal de l'univers jörai. Paris, JATBA-MNHN, $498 \mathrm{p}$.

Drouin J.-M. 2008 - L'herbier des philosophes. Paris, Seuil, 314 p.

Drury H. 1873 - The useful plants of India; with notices of their chief value in commerce, medicine, and the arts. London, Allen, $512 \mathrm{p}$.

Ellen R. 1993 - The cultural relations of classifications - An analysis of Nuaulu Animal Categories from Central Seram. Cambridge University Press, $315 \mathrm{p}$.

Ellen R. (Ed.) 2006 - Ethnobiology and the science of humankind. Blackwell/Royal Anthropological Institute (JRAI spécial issue 1), $202 \mathrm{p}$.

Ellen R., Stimson A.F. \& Menzies J. 1977 - The content of categories and experience: the case for some Nuaulu reptiles. JATBA $24: 3-22$.

Ember M. 1988 - The human relations area files: Past and future. Behavior Science Research 22 (1-4) : 97-104.

Fewkes J.W. 1896 - A contribution to ethnobotany. American Anthropologist 9 (1) : 14-21.

Filhol H. 1894 - Conseils aux voyageurs naturalistes : publication consécutive aux leçons faites au Muséum d'histoire naturelle en 1893. Paris, Imprimerie nationale, $302 \mathrm{p}$.

Ford R.I. 2011 - History of ethnobiology. In : Anderson E.N. et al. (Ed.), Ethnobiology : 15-26. 
Fosberg F.R. 1948 - Economic botany-A modern concept of its scope. Economic Botany 2 (1) : 3-14. Frake C.O. 1962 - Cultural ecology and ethnography. American Anthropologist 64 (1) : 53-59.

Friedberg C. 1968 - Les Méthodes d'Enquête en Ethnobotanique. Comment mettre en évidence les taxonomies indigènes ? JATBA XV (7-8) : 297-324.

Friedberg C. 1974 - Les processus classificatoires appliqués aux objets naturels et leur mise en évidence. Quelques principes méthodologiques. JATBA XXI (10/11/12) : 313-334.

Friedberg C. 1990 - Le savoir botanique des Bunaq (Timor, Indonésie). Paris, MNHN, 304 p.

Friedberg C. 2005 - Ethnoscience et autres ethno « machins » aujourd'hui. Journal de la Société des Océanistes 120 (1) : 27-30.

Fuchs L. 2016 - Le nouvel Herbier de 1543. Cologne, Taschen, 960 p.

Gayon J. 1997 - Le Muséum national d'Histoire naturelle et l'amélioration des plantes au XIXème siècle. In : Blanckaert C. et al. (Ed.), Le Muséum au premier siècle de son histoire. Paris, Muséum national d'Histoire naturelle : 375-402. (Archives).

Gilmore M.R. 1911-1912 - Uses of plants by the Indians of the Missouri River region. In : $33^{\text {th }}$ annual report of Bureau of American Ethnology : 43-154.

Gilmore M.R. 1932a - The Ethnobotanical Laboratory at the University of Michigan. Ann Arbor, University of Michigan Museum Anthropology, $37 \mathrm{p}$.

Gilmore M.R. 1932b - Importance of ethnobotanical investigation. American Anthropologist 34 (2) : 320-327.

Goyder D., Griggs P., Nesbitt M., Parker L. \& Ross-Jones K. 2012 - Sir Joseph Hooker's collections at the Royal Botanic Gardens, Kew. Curtis's Botanical Magazine 29 (1) : 66-85.

Grenand P. 1980 - Introduction à l'étude de l'univers wayãpi : ethnoécologie des Indiens Wayãpi du haut Oyapock (Guyane). Paris, SELAF, $332 \mathrm{p}$.

Grenier L. 1998 - Connaissances indigènes et recherche : un guide à l'intention des chercheurs. Ottawa, CRDI, $120 \mathrm{p}$.

Guillaumin A. 1923 - Les cultures en Océanie française. RBA 3 (21) : 322-327.

Guillaumin A. 1929-1936 - Les fleurs de jardins. Paris, Lechevalier, 4 vol.

Guillaumin A. 1931 - Les cactées cultivées. Paris, La Maison rustique, 194 p.

Guillaumin A. 1933 - La chaire de culture du Muséum national d'histoire naturelle de Paris (cours inaugural). Revue scientifique 71 (12) : 353-361.

Guillaumin A. 1944 - Patates et Ignames dans la région parisienne et plus au Nord. RBA 24

(272-274) : 165-171.

Guillaumin A. 1946a - Désiré Bois (1856-1946). Bulletin de la Société Botanique de France 93 (3-4) : 115-118.

Guillaumin A. 1946b - Les plantes cultivées : histoire, économie. Paris, Payot, 352 p.

Guillaumin A.1970 - Le Santal en Nouvelle-Calédonie. JATBA 17 (7-9) : 340-341.

Guillaumin A. \& Haudricourt A.-G. 1961 - Contributions à la flore de la Nouvelle Calédonie CXIX. Plantes récoltées par A. Haudricourt. JATBA 8 (8-9) : 348-355.

Guillaumin A. \& MacKee H.S. 1956 - Notes sur quelques plantes utilisées par les Indigènes en Nouvelle-Calédonie. JATBA 3 (12) : 887-890. 
Guille-Escuret G. 1997 - Jacques Barrau : un naturaliste au milieu des hommes (1925-1997). Journal de la Société des Océanistes 105 (2) : 209-211.

Hamel J.L. 1976 - André Guillaumin (1885-1974). Bulletin de la Société Botanique de France 123 (1-2) : 89-93.

Hamy E.-T. 1988 [1890] - Les origines du Musée d'ethnographie. Paris, J.-M. Place, iv+321 p.

Harshberger J.W. 1896a - The purposes of Ethno-Botany. Botanical Gazette 21 (3) : 146-154.

Harshberger J.W. 1896b - Ethno-botanic gardens. Science 3 (58) : 203-205.

Harshberger J.W. 1927 - Traité de Geographie Physique, par E. de Martonne. Tome 3 :

Biogéographie (en collaboration avec A. Chevalier et L. Cuénot). Science 66 (1705) : 218-218.

Haudricourt A.-G. 1956 - Une discipline nouvelle : l'ethno-botanique. Les Cahiers Rationalistes 158 : 293-294.

Haudricourt, A.-G. \& Hédin L. 1943 - L'homme et les plantes cultivées. Paris, Gallimard, 234 p. [Réed. 1987, Paris, A.-M. Métailié, 282 p.]

Haudricourt A.-G. \& Hédin L. 1953 - Recherches récentes sur l'histoire des plantes cultivées. RBA $33(373-374)$ : 537-545.

Heim R. 1968 - Notice nécrologique sur Henri Humbert (1887-1967). C. R. Acad. Sc. Paris 266 : 36-40. Henderson J. \& Harrington J.P. 1914 - Ethnozoology of the Tewa Indians. Washington, Smithsonian Institution Bureau of American ethnology, 76 p.

Hernández F. 1651 - Rerum medicarum Novae Hispaniae thesaurus. Rome, 464 p.

Hoare C. 2012 - Le JATBA et ses ancêtres. Essai d'histoire de la revue d'un laboratoire du Muséum national d'histoire naturelle. Revue d'ethnoécologie 1 [en ligne] doi.org/10.4000/ethnoecologie.673

Hoare C. \& Lizet B. 2008 - Soulever quelque coin du voile des ténèbres de l'Afrique. La mission Chari-lac Tchad (Afrique Centrale Française) d'Auguste Chevalier 1902-1904. Les Carnets du paysage $16: 160-183$.

Hooker W. 1849 - Botany. In : Herschel J. F.W. (Ed.) A manual of scientific enquiry. Londres, Murray : 400-422.

Hooker W.J. 1851 - Kew Gardens; or a popular guide to the Royal Botanic Gardens in Kew. London, Longman, 60 p. [facsimile par Forgotten Books 2012]

Hooker W.J. 1855 - Museum of economic botany or, a popular guide to the useful and remarkable vegetable products of the museum or the Royal Gardens of Kew. London, Longman, $80 \mathrm{p}$.

Hough W. 1897 - The Hopi in relation to their plant environment. American Anthropologist 10 (2) : 33-44.

Hunn E.S. 1977 - Tzeltal folk-zoology: the classification of discontinuities in nature. NY, Academic Press, xliv $+368 \mathrm{p}$.

Hunn E.S. 2007 - Ethnobiology in four phases. Journal of Ethnobiology 27 (1) : 1-10.

Hunn E.S. 2011 - Ethnozoology. In : Anderson E.N. et al. (Ed.), Ethnobiology : 83-96.

Inglis J.T. (Ed.) 1993 - Traditional ecological knowledge: Concepts and cases. Ottawa, IDRC, 142 p.

Jacquet P. 1996 - Les botanistes lyonnais du XVI ${ }^{\mathrm{e}}$ siècle. Publications de la Société Linnéenne de Lyon $65(5): 1-70$ 
Jaussaud P. \& Brygoo É.-R. 2004 - Du jardin au Muséum en 516 biographies. Paris, Muséum National d'Histoire Naturelle, $630 \mathrm{p}$.

Johannes R.E. 1978 - Traditional marine conservation methods in Oceania and their demise. Annual review of Ecology and Systematics 9 (1) : 349-364.

Johannes R.E. 1981a - Working with fishermen to improve coastal tropical fisheries and resource management. Bulletin of Marine Science 31 (3) : 673-680.

Johannes R.E. 1981b - Words of the lagoon: fishing and marine lore in the Palau district of Micronesia. Berkeley, Univ of California Press, 245 p.

Johannes R.E. (Ed.) 1989 - Traditional ecological knowledge: a collection of essays. Gland, IUCN, 77 p. Johnson L.M. \& Hunn E.S. 2012 - Landscape ethnoecology : concepts of biotic and physical space. New York, Berghahn Books, Oxford, xi+320 p.

Jussieu A.L. de 1802 (an XI) - Notice historique sur le Muséum d'Histoire Naturelle, § 1, Depuis sa fondation jusqu'en 1643. Annales du Muséum national d'histoire naturelle I : 1-14.

Kleiche-Dray M. 2000 - Origine et mise en place de la recherche agronomique tropicale en France. CR l'Académie d'Agriculture de France 86 : 65-76.

Kuipers J. \& McDermott R. (Ed.) 2007 - Harold C. Conklin. Fine description. Ethnographic and linguistic essays. New Haven, Yale University Southeast Asia Studies, 511 p.

L'agriculture pratique... 1901 - Arrêté créant un bulletin du Jardin Colonial et des jardins d'essai des colonies françaises. L'agriculture pratique des pays chauds, bulletin du jardin colonial : 9

La Brosse G. de 1628 - De la natvre, vertv, et vtilité des plantes : divisé en cinq livres. Suivi de : Dessein d'vn iardin royal povr la cvltvre des plantes medicinales à Paris, où est amplement déduit la raison de la necessité, \& quel bien il peut apporter au public. Paris, Rollin Baragnes, 848 p.

Lacroix A. 1939 - Un grand botaniste français : Henri Lecomte (1856-1938) [sic, pour 1934]. Revue internationale de l'enseignement 93 (1) : 83-97.

Laissus Y. 1981 - Les voyageurs naturalistes du Jardin du roi et du Muséum d'histoire naturelle : essai de portrait-robot. Revue d'histoire des sciences 34 (3-4) : 259-317.

Lecomte H. 1897 - Notre programme. Revue des cultures coloniales I (1) : 4-5.

Lecomte H. 1923 - Les bois coloniaux. Paris, Armand Colin, 194 p.

Lepofsky D., Heckelsmiller C., Fernández-Llamazares Á. \& Wall J. 2021 - Seeking a More Ethical Future for Ethnobiology Publishing: A 40-Year Perspective from Journal of ethnobiology. Journal of Ethnobiology 41 (2) : 122-143, 122.

Letouzey Y. 1989 - Le Jardin des plantes à la croisée des chemins : avec André Thouin, 1747-1824. Paris, Éditions du Muséum, $678 \mathrm{p}$.

Lévi-Strauss C. 1950 - The use of wild plants in tropical South America. In : Steward J. (Ed.), Handbook of South American Indians VI : 465-486.

Lévi-Strauss C. 1962 - La pensée sauvage. Paris, Plon, 396 p.

Lindley J. 1849 - Medical and Economical Botany. London, Bradbury and Evans, 274 p.

Linné C. von 1787 - Materia medica. Leipzig, Walther, 318 p.

Magnin-Gonze J. 2009 - Histoire de la botanique. Paris, Delachaux et Niestlé, 264 p.

Majnep I.S. \& Bulmer R. 1977 - Birds of My Kalam Country. Auckland University Press, 219 p. 
Martin M.A. 1975 - L'ethnobotanique, science per se ? JATBA XXII (7/8/9) : 237-276.

Martin M.A. 1997 - Les Khmers Daeum, « Khmers de l'origine » : société montagnarde et exploitation de la forêt : de l'écologie à l'histoire. Paris, École Française d'Extrême-orient, 515 p.

Mason O.T. 1899 - Aboriginal American zoötechny. American Anthropologist 1 (1) : 45-81.

May M.A. 1971 - A retrospective view of the Institute of Human Relations at Yale. Behavior Science Notes 6 (3) : 141-172.

McAlvay A.C., Armstrong C.G., Baker J., Elk L.B., Bosco S., Hanazaki N., Joseph L., Martínez-Cruz T.E., Nesbitt M., Palmer M.A., Priprá de Almeida W.C., Anderson J., Asfaw Z., Borokini I.T., CanoContreras E.J., Hoyte S., Hudson M., Ladio A.H., Odonne G., Peter S., Rashford J., Wall J., Wolverton S. \& Vandebroek I. 2021 - Ethnobiology Phase VI: Decolonizing Institutions, Projects, and Scholarship. Journal of Ethnobiology 41 (2) : 170-191, 122.

McGee W. 1897 - The beginning of zooculture. American Anthropologist 10 (7) : 215-230.

Meilleur B. 1986 - Alluetian ethnoecology and traditional economy: the procurement and production of plant resources in the Northern French Alps. Seattle, PhD, Université de Washington.

Messinger Ramos S. \& Ramos A. (Ed.) 2004 - Garcia de Orta, Colloques des simples et des drogues de l'Inde, traduction du portugais S. Messinger Ramos, A. Ramos \& F. Marchand-Sauvagnargues. Arles, Actes sud, $732 \mathrm{p}$.

Métailié G. 1989 - Histoire naturelle et humanisme en Chine et en Europe au XVI siècle : Li Shizhen et Jacques Dalechamp. Revue d'histoire des sciences : 353-374.

Milhe-Poutingon A. 1897 - La renaissance des cultures coloniales. Revue des cultures coloniales I (1) : 1-3.

Moller H., Berkes F., Lyver P.O. \& Kislalioglu M. 2004 - Combining science and traditional ecological knowledge: Monitoring populations for co-management. Ecology and Society 9 (3) : 15 p. (online).

Monardes N. 1580 - Primera y secunda y tercera partes de la Historia Medicinal : de las cosas que se traen de nuestras Indias Occidentales, que sirven en Medicina. Séville, Fernando Diaz, 162 folio.

Murdock G.P. 1940 - The cross-cultural survey. American Sociological Review 5 (3) : 361-370.

Murdock G.P. 1954 - Outline of world cultures. New Haven, Human Relations Area Files, 180 p.

Murdock G.P., Ford C., Hudson A., Kennedy R., Simmons L. \& Whiting J. 1965 - Outline of cultural materials ( $4^{\text {th }}$ revised edition, with modifications). New Haven, Human Relations Area Files, $164 \mathrm{p}$.

Nesbitt M. \& Cornish C. 2016 - Seeds of industry and empire: economic botany collections between nature and culture. Journal of Museum Ethnography 29 : 53-70.

O’Reilly P. 1974 - André Guillaumin (1885-1974). Journal de la Société des océanistes 44 : 243-244.

Orta G. de1563 - Coloquios dos simples, e droga he cousas mediçinais da India..., Goa, 217 folio

Paillieux A. \& Bois D. 1899 - Le potager d'un curieux : histoire, culture et usages de 250 plantes comestibles peu connues ou inconnues. Paris, La maison rustique, XVI + 678 p.

Panoff M. 1988 - Ralph Bulmer (1928-1988). Journal de la Société des Océanistes 86 (1) : 89-90.

Portères R. 1955a - Activité du Laboratoire d'Agronomie Tropicale en 1955. Travaux faits au Laboratoire pendant l'année 1955. JATBA 2 (12) : 687-688. 
Portères R. 1955b - Un problème d'Ethno-botanique : relations entre le Riz flottant du Rio-Nunez et l'origine médinigérienne des Baga de la Guinée Française. JATBA 2 (10-11) : 538-542.

Portères R. 1957 - Rapport sur l'activité du Laboratoire d'Agronomie Tropicale en 1956. JATBA 4 (1-2) : 108-109.

Portères R. 1961. L'ethnobotanique : place - objet - méthode - philosophie. JATBA 8 :102-109.

Portères R. 1966 - Aspects de l'Ethnobotanique comme discipline scientifique affirmée. JATBA XIII (12) : 701-704.

Portères R. 1969-1970 - Cours d'ethno-botanique générale. Paris, MNHN, Laboratoire d'ethnobotanique et d'ethno-zoologie, $151 \mathrm{p}$.

Posey D.A. 1981 - Wasps, warriors and fearless men: ethnoentomology of the Kayapó Indians of Central Brazil. Journal of Ethnobiology 1 (1) : 165-174.

Posey D.A. 1982 - Ethnomethodology as an emic guide to cultural systems: the case of the insects and the Kayapó Indians of Amazonia. Revista Brasileira de Zoologia 1 :135-144.

Posey D.A. \& Dutfield G. 1996 - Beyond intellectual property. Toward traditional resource rights for indigenous peoples and local communities. Ottawa, International development research centre, $303 \mathrm{p}$.

Posey D.A., Frechione J., Eddins J., Francelino da Silva L., Myers D., Case D. \& Macbeath P. 1984 Ethnoecology as applied anthropology in Amazonian development. Human Organization 43 (2) : 95-107.

Powers S. 1873-1874 - Aboriginal Botany. Proceedings of the California Academy of Science 5 : 371-379. Prance G.T. 2001 - Richard Evans Schultes (12 January 1915-10 April 2001): A tribute. Economic Botany 55 (3) : 347-362.

Pujol R. 1969-1970 - Cours d'ethnozoologie : Initiation à l'ethnozoologie ; méthodes. Paris, MNHN, laboratoire d'ethnobotanique et d'ethnozoologie, $41 \mathrm{p}$.

Pujol R. \& Carbone G. 1990 - L'homme et l'animal. In : J. Poirier (Ed.) Histoire des moeurs I, Encyclopédie de la Pléiade. Paris, Gallimard : 1307-1388.

Raponda-Walker A. \& Sillans R. 1961 - Les plantes utiles du Gabon. Paris, Lechevalier, X+ 614 p.

Revel N. 1990a - Fleurs de paroles. Histoire naturelle Palawan. I Les dons de Nägsalad. Paris, Peeters/ Selaf, $374 \mathrm{p}$.

Revel N. 1990b - Fleurs de paroles. Histoire naturelle Palawan. II La maîtrise d'un savoir et l'art d'une relation. Paris, Peeters/Selaf, $322 \mathrm{p}$.

Revel-Macdonald N. 1983 - L'œuvre de H. C. Conklin : étude des savoirs traditionnels des montagnards aux Philippines. Études rurales : 231-237.

Rivet P. 1936 - Ce qu'est l'ethnologie. In : Rivet P. (Ed.) L'espèce humaine, vol. VII de L'Encyclopédie française. Paris, Larousse : 7.06.1-7.06.8 et 7.08.1-7.08.16.

Robbins W.J. 1947 - Why Another Botanical Magazine? Economic Botany 1 (1) : 3-4.

Robbins W.W., Harrington J.P. \& Freire-Marreco B. 1916 - Ethnobotany of the Tewa Indians. Washington, Smithsonian Institution Bureau of American ethnology, $118 \mathrm{p}$.

Rochebrune A.T. de 1879 - Recherches d'ethnographie botanique sur la flore des sépultures péruviennes d'Ancon. Actes de la société Linnéenne de Bordeaux 5 (20) : 343-358. 
Roué M. \& Nakashima D. 2002 - Des savoirs « traditionnels » pour évaluer les impacts environnementaux du développement moderne et occidental. Revue internationale des sciences sociales $173: 377-387$.

Rousseau J. 1961. Le champ de l'ethnobotanique. JATBA 8 : 93-101.

Rousseau J. \& Raymond M. 1945 - Études ethnobotaniques québécoises. Montréal, Institut de botanique, 154 p. (Contribution $\mathrm{n}^{\circ} 55$ ).

Ruddle K., Hviding E. \& Johannes R.E. 1992 - Marine resources management in the context of customary tenure. Marine Resource Economics 7 (4) : 249-273.

Schultes R.E. 1936 - Peyote and plants used in the peyote ceremony. Botanical Museum Leaflets Harvard Univ. 4 :129-152.

Schultes R.E. 1951 - Le Paullinia yoco el son emploi comme stimulant. RBA 31 (343-344) : 279-290.

Schultes R.E. 1954 - Un nouveau Tabac à priser de l'Amazone du Nord-Ouest. JATBA 1 (7-9) : 298-311.

Schultes R.E. 1979 - The Amazonia as a Source of New Economic Plants. Economic Botany 33 (3) : 259-266.

Schultes R.E. 1984 - The botanical museum of Harvard University in its 125th year 1858-1983. Botanical Museum Leaflets, Harvard University 30 (1) : 1-11.

Sillitoe P. 1998 - The development of indigenous knowledge: a new applied anthropology. Current Anthropology 39 : 223-252.

Société Internationale d'Ethnobiologie 2006 - Code d'Éthique de la SIE (avec les ajouts de 2008). En ligne : http://ise.arts.ubc.ca/global_coalition/ethics.php

Spoehr A. 1985 - George Peter Murdock (1897-1985). Ethnology 24 (4) : 307-317.

Stevenson M.C. 1908-1909 - Ethnobotany of the Zuñi Indians. 30 ${ }^{\text {th }}$ Annual report of the Bureau of American Ethnology.Washington, Smithsonian Inst. : 35-102.

Steward J.H. 1937 - Ecological aspects of Southwestern society. Anthropos 32 (1/2) : 87-104.

Steward J.H.1938 - Basin-plateau aboriginal sociopolitical groups. Bureau of American ethnology, 346 p. (Bulletin 120).

Steward J. 1949 - Handbook of South American Indians, Vol. V, The comparative ethnology of South American Indians, xxvi+818 p. (Bulletin of American Ethnology ; 143).

Steward J. 1955 - Theory of culture change. The methodology of multilinear evolution. Urbana, University of Illinois Press, $244 \mathrm{p}$.

Steward J. 1968 - Cultural ecology. In : Sills D., International encyclopedia of the social sciences. New York, The MacMillan Co : 337-344.

Sturtevant W.C. 1964 - Studies in Ethnoscience. American Anthropologist 66 (3-2) : 99-131.

Thouin A. 1827 (posthume) - Cours de culture et de naturalisation des végétaux (publié par Leclerc O.). Tome I. Paris, Huzard, 528 p.

Toledo V.M. 1992 - What is ethnoecology? Origins, scope and implications of a rising discipline. Etnoecológica $1: 5-21$.

Toledo V.M. \& Barrera-Bassols N. 2008 - La memoria biocultural: la importancia ecológica de las sabidurias tradicionales. Barcelone, Junta de Andalucia/Icaria editorial, $230 \mathrm{p}$. 
Toledo V.M., Barrera-Bassols N., Garcia Frapolli E. \& Alarcón-Cháires P. 2013 - Etnoecologia de los Mayas Yucatecos. Morelia, CONACYT, $26 \mathrm{p}$.

Tournefort J. Pitton de 1694 - Elémens de botanique : ou métode pour connoître les plantes. Tome premier. Paris, Imprimerie royale, $598 \mathrm{p}$.

Tournefort J. Pitton de 1698 - Histoire des plantes qui naissent aux environs de Paris, avec leur usage dans la médecine. Paris, Imprimerie royale, $543 \mathrm{p}$.

Vavilov N.I. (d'après) 1936 - Les bases botaniques et géographiques de la sélection (traduction de A.-G. Haudricourt). RBA XVI $(174,175,176)$ : 124-129, 214-223, 285-293.

Vestal P. \& Schultes R.E. 1939 - The economic botany of the Kiowa Indians as it relates to the history of the tribe. Cambridge, Harvard University Botanical Museum, xiii+110 p.

Volper S. \& Bichat H. 2014 - Des jardins d'essai au Cirad : une épopée scientifique française. Histoire de la recherche contemporaine III (2) : 113-124.

Watt G. 1889-1896 - A dictionary of the economic products of India. 6 volumes, Calcutta.

Wickens G.E. 1990 - What Is Economic Botany? Economic Botany 44 (1) : 12-28.

Wickens G.E. 1993a - Two centuries of Economic Botanists at Kew: Part 1. The Kew Magazine 10 (2) : 84-94.

Wickens G.E. 1993b - Two centuries of Economic Botanists at Kew: Part 2. The Kew Magazine 10 (3) : 132-138.

Wolverton S. 2013 - Ethnobiology 5: interdisciplinarity in an era of rapid environmental change. Ethnobiology letters $4: 21-25$.

\section{ANNEXES}

Tableau chronologique : Quelques étapes significatives des études sur les relations hommes et plantes

Code typographique : Institutions, termes, «Titre de publication » 


\begin{tabular}{|c|c|c|c|}
\hline Année & Personnage & Evènement & Lieu \\
\hline 1793 & A. Thouin & Chaire de culture & MNHN (Paris) \\
\hline 1813 & A. P. de Candolle & Botanique appliquée & Suisse \\
\hline 1847 & W. J. Hooker & Museum of Economic Botany & $\operatorname{Kew}(G B)$ \\
\hline 1858 & A. Gray & Museum of vegetable products & Harvard (USA) \\
\hline 1873 & S. Powers & Aboriginal botany & USA \\
\hline 1879 & A. de Rochebrune & Ethnographie botanique & MNHN (Paris) \\
\hline 1883 & A. de Candolle & "Origine des plantes cultivées" & Paris \\
\hline 1896 & J. Harshberger & "The purpose of ethno-botany" & USA \\
\hline 1899 & H. H. Rusby & Museum of Economic Botany & NYBG (USA) \\
\hline 1911 & A. Chevalier & Laboratoire d'agronomie coloniale & EPHE (Paris) \\
\hline 1916 & J. Harrington et al. & "Ethnobotany of the Tewa Indians" & USA \\
\hline 1921 & A. Chevalier & "Revue de botanique appliquée et d'agriculture coloniale " & MNHN (Paris) \\
\hline 1929 & A. Chevalier & Chaire d'agronomie coloniale & MNHN (Paris) \\
\hline 1930 & M. R. Gilmore & Ethnobotanical laboratory, U Michigan & Ann Arbor U (USA) \\
\hline 1935 & E. F. Castetter & "The Ethnobiology of the Papago Indians" & U New Mex. (USA) \\
\hline 1943 & A. G. Haudricourt \& L. Hédin & "L'homme et les plantes cultivées" & MNHN (Paris) \\
\hline 1944 & E. F. Castetter & "The domain of Ethnobiology" & U New Mex. (USA) \\
\hline 1947 & H. Gleason \& E. Fulling & "Economic Botany" (journal) & NYBG (USA) \\
\hline 1954 & H. Conklin & "An ethnoecological approach to shifting agriculture" & USA \\
\hline 1954 & H. Conklin & "The relation of Hanunbo culture to the plant world" & Yale Univ. (USA) \\
\hline 1954 & G.P. Murdock & Ethnoscience & Yale Univ. (USA) \\
\hline 1954 & R. Portères et al. & "Journal d'Agriculture Tropicale et de Botanique Appliquée " & MNHN (Paris) \\
\hline 1959 & & Society for Economic Botany & USA \\
\hline 1961 & C. Lévi Strauss et al. & "L'Homme. Revue française d'anthropologie " & Collège de France (Paris) \\
\hline 1962 & C. Lévi Strauss & "La pensée sauvage" & Paris \\
\hline 1963 & R. Portères & Laboratoire d'ethnobotanique & MNHN (Paris) \\
\hline 1974 & B. Berlin et al. & "Principles of Tzeltal plant classification" & USA \\
\hline 1980 's & R. E. Johannes & Traditional ecological knowledge & USA \\
\hline 1981 & D. Posey et al. & "Journal of Ethnobiology" & USA \\
\hline 1988 & D. Posey et al. & International Society for Ethnobiology (ISE) & Belèm (Brésil) \\
\hline 1990 & C. Friedberg & "Le savoir botanique des Bunaq" & MNHN (Paris) \\
\hline 1992 & ONU & La convention pour la diversité biologique & Rio de Janeiro (Brésil) \\
\hline 1992 & V. Toledo & "What is Ethnoecology?" & Mexique \\
\hline 1994 & W. Balée & "Footprints of the forest: Ka'apor ethnobotany" & USA \\
\hline 2005 & Ph. Descola & "Par-delà nature et cuiture » & Paris \\
\hline 2006 & ISE & Code of Ethics & \\
\hline 2010 & ONU & Protocole de Nagoya & Nagoya (Japon) \\
\hline 2012 & ONU & Rio +20 & Rio de Janeiro (Brésil) \\
\hline 2012 & S. Bahuchet et $a$ l. & "Revue d'ethnoécologie " & MNHN (Paris) \\
\hline
\end{tabular}

\section{NOTES}

1. Sur cette mission, voir Hoare \& Lizet (2008).

2. L'École nationale supérieure d'Agriculture coloniale (ENSAC) deviendra en 1921 l'Institut national d'agronomie coloniale.

3. Fondée en 1894 à l'initiative «d'un certain nombre d'armateurs, d'exportateurs, d'industriels, de sociétés minières et commerciales, (...) » l'Union coloniale française est un organisme nouveau qui est devenu « la Chambre syndicale du Commerce colonial» (Chambre syndicale ... 1894: n. p.). A. Milhe-Poutingon, docteur en droit, était chargé du service de l'Afrique à l'Union coloniale. Voir Brunschwig 1959, Bonneuil \& Kleiche 1993.

4. "Agronome russe réfugié en France", J. Vilbouchevitch avait remplacé Lecomte comme rédacteur de Revue des cultures coloniales, où il ne resta que deux ans par suite de différends avec le directeur (comme Lecomte avant lui !). (AC $1943: 2$ ).

5. Sa Relation d'un voyage du Levant (1717, édition posthume) en est un bel exemple, qui décrit les lieux, les plantes « rares », les animaux et « le génie, les mours, le commerce \& la religion des differens peuples qui les habitent ».

6. Chevalier a consacré un livre entier à Michel Adanson (1934b).

7. Sur les voyageurs-naturalistes du Jardin du Roy, voir Laissus (1981).

8. De 1921 à 1956, l'année même de sa mort, Chevalier a publié 429 articles dans sa revue !

9. On trouvera les principales dispositions de l'Édit royal dans Jaussaud \& Brygoo (2004 : 545 ).

10. On n'oubliera pas que Le malade imaginaire et son Docteur Diafoirus voient le jour le 10 février 1673 ! Cela donne une bonne idée de la renommée de la Médecine au XVII siècle.

11. L'enseignement (les "démonstrations») au Jardin du Roy est assuré par des "démonstrateurs", assistés le cas-échéant de "sous-démonstrateurs ». Ultérieurement, tous ces savants seront appelés « Professeurs".

12. Chevalier a consacré un long article à Guy-Crescent Fagon (1935c). 
13. Les titulaires sont respectivement René Desfontaines, Antoine-Laurent de Jussieu, André Thouin et Antoine Brongniart. Chevalier a consacré un ouvrage à Desfontaines.

14. Les arts chimiques concernent les "corps organiques ", ce qui comprend les végétaux. Une autre chaire est créée, de chimie générale. Concernant l'anatomie, deux chaires sont fondées, anatomie humaine (héritière de celle du Jardin du Roy) et anatomie des animaux.

15. André Thouin était auparavant le jardinier en chef du Jardin du Roy.

16. En particulier, Thouin réalisa des boutures de vanille dans ses serres du Muséum et en envoya à la Réunion en 1822, où elles prospérèrent. Même si à ce moment on ignorait le procédé de fertilisation, c'est à l'origine des cultures de vanille dans cette île et à Madagascar.

17. Sur Maxime Cornu, voir Bureau 1901.

18. Sur Désiré Bois, voir Guillaumin 1946a.

19. Sur André Guillaumin, voir Hamel 1976. Il a été professeur de 1932 à 1956.

20. Sur la Nouvelle Calédonie voir O'Reilly (1974).

21. Voir en particulier Guillaumin 1929-1936, 1931, 1946 b.

22. Henri Lecomte a été professeur de 1906 à 1931. La première partie de sa carrière s'effectue en Afrique équatoriale (Congo, Gabon, 1893), il se dédie ensuite à l'agriculture coloniale, au Gabon puis en France. Il rédige des manuels (cacao, café, coton, vanille...) et devient brièvement rédacteur en chef de la Revue des cultures coloniales. Il prend ensuite la tête du nouveau laboratoire colonial en 1902 (étant ainsi le prédécesseur de Chevalier), il s'y occupe des plantes utiles, à latex, à fibres, etc. Lorsqu'il devient professeur de botanique, il se consacre à la botanique systématique et aux herbiers, ainsi qu'à l'anatomie du bois (Lecomte 1923). Ce faisant il étudie des collections que Chevalier avait recueillies en Indochine, et les publiera. Sur Lecomte, voir Chevalier 1934c, Lacroix 1939.

23. Botaniste de terrain, Henri Humbert (professeur de 1931 à 1933) a étudié la flore malgache, mais surtout la végétation des hautes montagnes, effectuant d'innombrables missions sur tous les continents. Il en observe toutes les facettes, taxonomie, phytogéographie, écologie... y compris l'influence des activités humaines sur la végétation et la question de la protection de la nature. Selon Aymonin (1967), c'était un «explorateur intrépide, un montagnard dont la hardiesse trouvait sa raison d'être dans l'acquisition de nouvelles connaissances». Sur Humbert voir Aymonin 1967, Heim 1968.

24. [...] tenho grande desejo de saber das drogas medicinais (as que chamão lá em Portugal de botica) e destoutras mezinhas simples que qua ha, ou fruitas todas, e da pimenta, das quais cousas queria saber os nomes em todas as lingoas, assi das terras donde nascem, e dos arvores ou prantas que as crião : e assi queria saber como usão dellas os fisicos Indianos, e tambem queria saber dalgunas outras plantas e frutos desta terra, ainda que não sejão medicinais, e assi dalguns custumes desta terra, ou cousas que nella acontecerão : e porque todas estas cousas ham de ser ditas na verdade, e vistas per vos ou per pessoas dinas de fee. (Orta $1563: 1$ ).

25. Allende destas riquezas tan grandes, nos embian nuestras Indias Occidentales, muchos arboles, plantas, yeruas, rayzes, çumos, gomas, frutos, simientes, licores, piedras que tienen grandes virtudes medicinales, enlas quales se han hallado, $y$ hallan muy grandes efetos que exceden mucho en valor y precio, a todo lo susodicho, tanto quanto es mas excelente y necessaria, la salud corporal, que los bienes temporales : de las quales cosas, todo el mundo carecia, no sin pequeña falta nuestra, segun los grandes provechos que vemos que del uso dellas se consiguen, no solo en nuestra España, pero en todo el mundo. (Monardes 1580, p. 1, $\mathrm{V}^{\circ}$ )

26. Nous utilisons ici la traduction en français réalisée par son assistant Jean Desmoulins (Histoire générale des plantes), publiée seulement en 1615.

27. Sur Daléchamps et son œuvre botanique, Desmoulins et les botanistes de son temps, cf. Jacquet (1996). Sur les classifications de Daléchamps, cf. Métailié (1989).

28. Peu après Gaspar Bauhin publie à son tour une gravure de la plante qu'il nomme Solanum tuberosum esculentum (Prodromos theatri botanici, $1620: 89$ ). 
29. Innombrables sont les plantes qu'Alphonse de Candolle a décrites et qui portent encore ses initiales d'auteur, A.DC, comme celles décrites par son père Augustin-Pyrame, aux initiales DC.

30. Tome 2 , livre second, chapitre IX « Origine géographique des espèces cultivées », pp. 809-993.

31. Le traducteur, A. G. Haudricourt, conclut ainsi : « Pour achever l'œuvre de M. Vavilov, il faut étudier les plantes tropicales de la même façon qu'il a étudié les plantes des pays tempérés. Il faudrait que la France, l'Angleterre et la Hollande créent un organisme international qui réunisse l'assortiment mondial de chaque plante tropicale ». (In Vavilov 1936 : 293).

32. "This collection of interesting and economic vegetable substances is rapidly, and we may say daily, increasing (...)». (Hooker $1851: 4)$

33. Sur l'histoire de la botanique économique à Kew Gardens, voir Wickens (1993a et b).

34. Sur le Museum of economic botany et les collections de botanique économique, voir Center for Economic Botany (s.d.).

35. Colonel Heber Drury (1819-1905) ; George Watt (1851-1930).

36. Les archives d'A. Chevalier, comprenant sa correspondance, demandent encore un dépouillement et une analyse spécifique, en particulier pour détailler tous ses contacts.

37. La RBA ("fondée en 1901 », sic) est citée parmi les rares périodiques qui se consacrent aux valeurs économiques du royaume végétal (Robbins $1947: 3$ ).

38. "The intensity of involvement ranges from in-depth knowledge on the of plants in the wild (ethnobotany) through to an appreciation of the requirements for commercial product » (1990 : 15).

39. «Economic botany has already been defined as the study of economic plants, an umbrella definition that must also include ethnobotany. I prefer to consider ethnobotany as the study of useful plants prior to their commercial exploitation and eventual domestication » $(1990: 17)$.

40. Voir Clément (1998) sur l'ethnobotanique et l'ethnobiologie ; on pourra également consulter le cours donné par R. Portères qui comporte des résumés détaillés des positions des différents auteurs historiques (1969-70, accessible en ligne: https://cel.archives-ouvertes.fr/ cel-00654364/). Plus récemment voir Ford (2011).

41. Harrington avait publié auparavant une étude d'ethnozoologie sur les animaux chez les Tewa avec le zoologue Junius Henderson (1865-1937), (Henderson \& Harrington 1914).

42. Par la suite, Harshberger n'abordera plus ce domaine et se consacrera à la botanique, à la phytogéographie et aux forêts. Signalons qu'il a publié en 1927 un compte-rendu du Traité de géographie physique auquel Chevalier avait contribué, et il mentionne le chapitre comportant l'essai de classification des systèmes de culture.

43. Un article de Schultes est publié dans la RBA (1951) puis un second dans le premier volume du JATBA en 1954.

44. L'Abbé gabonais André Raponda-Walker (1871-1968) était un correspondant de longue date de Chevalier, qui l'a beaucoup publié dans la RBA. Erudit et multidisciplinaire, pionnier de l'ethnobotanique africaine, on lui doit Les plantes utiles du Gabon (1961), co-écrit avec Roger Sillans.

45. Sur l'œuvre ethnobiologique de Haudricourt, voir Barrau 1973.

46. Dès 1936, Paul Rivet mentionnait que A.-G. Haudricourt avait bénéficié d'une bourse de l'Institut d'ethnologie afin de réaliser en 1934 son premier voyage en Russie auprès de Nicolas Vavilov, pour y « étudier des problèmes d'ethno-botanique » (Rivet $1936: 708-5)$. C'est au retour de cette mission que Haudricourt compose son livre fondateur avec Louis Hédin.

47. En 1953, dans leur article sur les recherches récentes sur l'histoire des plantes cultivées, Haudricourt \& Hédin définissent dès la première ligne «L'ethnobotanique peut se définir comme l'étude des relations générales et réciproques de l'Homme et du monde végétal. » (537). Plus loin, le premier thème s'intitule « De l'ethnobotanique des Mils et des Millets » (Haudricourt \& Hédin 1953 : 538). Haudricourt avait défini « une discipline nouvelle : l'ethno-botanique ». 
48. On sait qu'il opère cette mutation dans le contexte du développement des instituts spécialisés dans l'agronomie des tropiques et de la décolonisation, prenant acte du fait que le MNHN n'était plus le lieu d'une recherche scientifique appliquée dans ce domaine. Sur l'influence de Haudricourt sur Portères pour la création de la chaire d'ethnobotanique, voir Bahuchet \& Lizet 2003.

49. Sur Jacques Barrau, voir Guille-Escuret (1997).

50. Dans le Volume VI du Handbook, Claude Lévi-Strauss écrit le chapitre sur les plantes : "The use of wild plants in tropical South America» (1950: 465-486); il n'utilise pas le vocable « ethnobotanique » dans ce chapitre extrêmement documenté.

51. Au moment de mettre sous presse ce numéro 20 , nous apprenons le décès de l'un des critiques importants de la cultural ecology, Andrew P. Vayda (1931-15/1/2022), tristement, l'année même du cinquantenaire de la revue majeure qu'il avait créée en 1972, Human Ecology: an interdisciplinary journal. À partir de ses terrains en Océanie et en Asie, Vayda a prôné, développé et encouragé une ecological anthropology à travers de très nombreuses publications, dont Human ecology accueille des exemples probants.

52. Wickens (1990: 19) fait remarquer que l'évolution des titres du JATBA accompagne l'évolution de la discipline en France: "The changing titles well illustrate the adjustment from colonial to noncolonial France, from tropical agriculture, ecology, and other aspects of applied botany to the ethnic needs of the French-speaking peoples».

53. Conklin a exposé lui-même son parcours et sa démarche scientifique (1998) ; un ouvrage lui a été consacré qui réunit un grand nombre de ses articles, introduits par des commentaires de ses collègues (Kuipers \& McDermott 2007). Sur l'œuvre ethnobiologique de Conklin, voir RevelMacdonald (1983).

54. Voir aussi Toledo et al. 2013 pour une étude chez les Maya.

55. Hunn revendique d'employer folk science plutôt qu'ethnoscience et le discute dans son ouvrage intitulé folk-zoology (et non « ethnozoology ») (1977: 3-5).

56. Sur Murdock, voir Spoehr (1985).

57. Outline of cultural materials a été régulièrement révisé et précisé ; l'exemplaire que nous avons consulté est la $4^{\mathrm{e}}$ révision ( $c f$. Murdock et al. 1965). La rubrique 82 est toujours en usage actuellement (https://hraf.yale.edu/resources/reference/outline-of-cultural-materials/ en ligne).

58. Sur l'évolution des concepts qui sous-tendent l'ethnoscience, on consultera la synthèse historique réalisée par Nicole Revel (Revel 1990a : 51-77).

59. «Un chercheur de terrain ne peut pas se satisfaire d'un simple catalogue des composantes d'un écosystème culturel selon les catégories de la science occidentale. Il doit aussi décrire l'environnement comme les gens eux-mêmes le construisent selon les catégories de leur ethnoscience. »

60. Citation complete : Ethnoscience differs from Simpson's "theoretical science" in that it refers to the "reduction of chaos" achieved by a particular culture, rather than to the "highest possible and conscious degree" to which such chaos may be reduced.

61. A titre d'exemples, pour rester dans le monde des plantes, on peut mentionner les études de Dournes au Laos (1968) ou de Meilleur dans les Alpes (1986). Pour des monographies qui prennent en compte l'ensemble des éléments du milieu, animaux et végétaux, Bahuchet (1985), Grenand (1980).

62. B. Berlin a poursuivi ses recherches en ethnoscience en l'appliquant aux termes de couleurs dans de nombreuses langues du monde, dans un ouvrage qui a eu un réel retentissement (Berlin \& Kay 1969).

63. Par la suite, Brent Berlin a affiné et précisé ses théories dans un ouvrage de synthèse sur les classifications ethnobiologiques (1992). 
64. Notons qu'indépendamment de la parution de l'ouvrage de Berlin et al., un colloque entièrement consacré aux classifications avait été organisé par les chercheurs du laboratoire d'ethnobotanique à la Maison des sciences de l'Homme à Paris, "Méthodes d'enquête ethnologique sur la conceptualisation et la classification des objets et phénomènes naturels ", tenu les 12 et 13 juin 1973. La plupart des communications a été publiée dans le JATBA ou dans la revue Information sur les sciences sociales.

65. Sur l'œuvre ethnobiologique de Claudine Friedberg (1933-2018), voir Bahuchet (2018).

66. Sur l'histoire de l'ethnozoologie, voir Hunn 2011. Les prémices, peu suivis, ont été zooculture proposée par McGee (1897) et aboriginal zoötechny par Mason (1899).

67. Sur Ralph Bulmer, voir Panoff 1988.

68. Sur Robert E. Johannes, voir Édition spéciale de Traditional marine resource management and knowledge Information Bulletin, Secretariat of the Pacific Community, Mars 2003, $31 \mathrm{p}$.

69. Tout spécialement l'article $8 \mathrm{j}$ qui stipule: "Article 8. Conservation in situ. Chaque Partie contractante, dans la mesure du possible et selon qu'il conviendra: (...) j) Sous réserve des dispositions de sa législation nationale, respecte, préserve et maintient les connaissances, innovations et pratiques des communautés autochtones et locales qui incarnent des modes de vie traditionnels présentant un intérêt pour la conservation et l'utilisation durable de la diversité biologique et en favorise l'application sur une plus grande échelle, avec l'accord et la participation des dépositaires de ces connaissances, innovations et pratiques et encourage le partage équitable des avantages découlant de l'utilisation de ces connaissances, innovations et pratiques".

70. Société Internationale d'Ethnobiologie 2006 - Code d'Éthique de la SIE (avec les ajouts de 2008). En ligne : http://ise.arts.ubc.ca/global_coalition/ethics.php

71. Código de Ética para la investigación, la investigación-acción y la colaboración etnocientífica en América Latina.

72. Sur l'évolution des phases de l'ethnobiologie, voir Clément (1998), Ford (2011) et D'Ambrosio (2014).

\section{RÉSUMÉS}

La Revue de Botanique Appliquée a été fondée en 1924 par Auguste Chevalier, directeur du laboratoire d'agronomie coloniale du Muséum national d'Histoire naturelle. Cet article resitue cette création dans le parcours scientifique de son fondateur et dans l'évolution du Muséum, en discutant de la place de l'étude des "plantes utiles » dès ses origines dans le jardin royal des plantes médicinales, puis dans les différents services liés à la botanique et à l'agriculture.

Plus globalement, nous replaçons l'expérience du Muséum de Paris dans une trame historique internationale, en rappelant l'émergence des divers courants tels que la botanique économique, l'ethnobotanique, l'ethnoecologie, l'ethnoscience et finalement l'ethnobiologie. Ce parcours international débute avec l'inventaire des plantes utiles jusqu'à l'étude des sociétés humaines en relation avec leurs milieux. Apparaît ainsi une diversité d'approches et de terminologies dans les différents centres académiques, approches qui cependant s'interpénètrent et s'influencent les unes les autres.

Revue de Botanique Appliquée was founded in 1924 by Auguste Chevalier, director of the colonial agriculture laboratory of the Muséum national d'Histoire naturelle, in Paris. This article 
recontextualizes the foundation of the journal within the scientific journey of its founder and, within the history of the Museum. We discuss the study of "useful plants" from the origins of the Museum in the Royal Garden for medicinal plants, and then in its various services related to botany and agriculture. More generally, we contextualize the experience of the Paris Museum within an international historical framework, recalling the emergence of various currents such as economic botany, ethnobotany, ethnoecology, ethnoscience and finally ethnobiology.

This international journey begins with the inventory of useful plants all the way to the study of human societies in relation to their environments. A diversity of approaches and terminologies emerges in the various academic centers, approaches which, however, interpenetrate and influence each other.

\section{INDEX}

Keywords : useful plants, trends and history of humanities disciplines, applied botany, economic botany, ethnobotany, ethnobiology

Mots-clés : plantes utiles, courants et histoire des disciplines de sciences humaines, botanique appliquée, botanique économique, ethnobotanique, ethnobiologie

\section{AUTEURS}

\section{SERGE BAHUCHET}

Professeur émérite, UMR Eco-anthropologie, Muséum national d'Histoire naturelle, Paris

\section{CATHERINE HOARE}

Ingénieur d'études, UMR Eco-anthropologie, Muséum national d'Histoire naturelle, Paris 